\title{
Self-Esteem and Relationship Satisfaction during the Transition to Motherhood
}

\author{
Manon A. van Scheppingen ${ }^{1}$, Jaap. J. A. Denissen ${ }^{1}$, Joanne M. Chung ${ }^{1}$, Kristian Tambs $^{3 \dagger}$, \& \\ Wiebke Bleidorn ${ }^{1,2}$ \\ ${ }^{1}$ Tilburg University, Netherlands \\ ${ }^{2}$ University of California, Davis, United States \\ ${ }^{3}$ Norwegian Institute of Public Health, Oslo, Norway \\ †'Deceased, 18 June 2017
}

To appear in: Journal of Personality and Social Psychology

Accepted Date: 25 May 2017

Author Note

Kristian Tambs passed away shortly before this manuscript went to press. We dedicate this manuscript to his memory.

The Norwegian Mother and Child Cohort Study is supported by the Norwegian Ministry of Health, the Norwegian Ministry of Education and Research, and the Norwegian Research Council/Functional Genomics (grant number 151918/S10). In addition, it is supported by the National Institute of Environmental Health Sciences (NIEHS, grant no N01-ES-85433) and the National Institute of Neurological Disorders and Stroke (NINDS, grant no.1 UO1 NS 047537-01 and grant no.2 UO1 NS 047537-06A1), which are part of the National Institutes of Health (NIH) of the United States.

Correspondence concerning this article should be addressed to Manon A. van Scheppingen, Department of Developmental Psychology, Tilburg University, PO Box 90153, 5000 LE Tilburg, The Netherlands. E-mail: m.a.vanscheppingen@uvt.nl

(C) 2017, American Psychological Association. This paper is not the copy of record and may not exactly replicate the final, authoritative version of the article. Please do not copy or cite without authors permission. The final article will be available, upon publication, via its DOI: $10.1037 / \mathrm{pspp} 0000156$. 


\section{Abstract}

In the current study, we used five waves of longitudinal data from a large representative sample of Norwegian mothers $(N=84,711)$ to examine the association between romantic relationship satisfaction and self-esteem before and after childbirth in subgroups of first-, second-, third-, and fourth-time mothers. Maternal self-esteem showed a highly similar changepattern across subgroups. Specifically, self-esteem decreased during pregnancy, increased until the child was six months old and then gradually decreased over the following years. The replication of this trajectory across subgroups and pregnancies suggests that this is a normative change pattern. For relationship satisfaction, the birth of the first child seemed to have the strongest impact compared to the birth of subsequent children. In first-time mothers, relationship satisfaction was high during pregnancy, sharply decreased around childbirth and then gradually decreased in the following years. In second-, third-, and fourth-time mothers, the decrease in relationship satisfaction after childbirth was more gradual and linear compared to the sharp decrease found in first-time mothers. Moderate positive correlated changes between self-esteem and relationship satisfaction indicated that these constructs were linked over time. Discussion focuses on the implications of the results for theory and future research on self-esteem, relationship satisfaction, and personality-relationship transactions. Keywords: self-esteem, relationship satisfaction, personality-relationship transactions, parenthood, MoBa 
During early adulthood, individuals encounter various life transitions and adopt new social roles, such as becoming a romantic partner, a full-time job holder or a parent. These roles are often associated with new behavioral demands and societal expectations (Roberts, Wood, \& Smith, 2005). Adapting to such role changes has been related to changes in both personality traits (Bleidorn, 2015; Bleidorn, Hopwood, \& Lucas, 2016; Roberts \& Wood, 2006; Roberts \& Jackson, 2008) and social relationships (Lang, Reschke, \& Neyer, 2006; Wrzus, Hänel, Wagner, \& Neyer, 2013).

Dynamic interactionism posits that changes in social relationships and personality mutually influence each other (Caspi \& Roberts, 2001; Magnusson, 1990, Neyer \& Asendorpf, 2001). That is, personality traits can influence how people select or change social relationships during normative life transitions, and at the same time, personality can change in response to the new experiences people have within relationships (i.e., personality-relationship transactions; Back et al., 2011; Caspi \& Roberts, 2001; Neyer \& Lehnart, 2007; Neyer \& Asendorpf, 2001). Such personality-relationship transactions might be especially strong for self-evaluative traits, such as self-esteem, because these traits are strongly linked to feelings of belonging and acceptance in social relationships (Denissen, Penke, Schmitt, \& van Aken, 2008; Leary \& Baumeister, 2000; Sciangula \& Morry, 2009).

The goal of the present study was to examine transactions between self-esteem and relationships during the transition to parenthood, a profound normative life experience that typically occurs during early adulthood. The transition to parenthood involves several biological, psychological, and social changes (Ross, Sellers, Gilbert Evans \& Romach, 2004) which are theorized to influence how new parents view themselves (Bleidorn, Buyukcan-Tetik, Schwaba, van Scheppingen, Denissen, \& Finkenauer, 2016) and how they view others, especially their 
romantic partners (Belsky \& Rovine, 1990; Doss, Rhoades, Stanley, \& Markman, 2009). For example, coping with the challenging task of caring for a baby can lead new parents to reflect and possibly re-evaluate the perceptions they hold for themselves and their partners in their new roles. Therefore, the transition to parenthood provides a relevant context for obtaining a deeper understanding of how self-esteem and social relationships co-develop over time (Lang et al, 2006).

Short- and long-term impacts of the transition to parenthood on mothers' self-esteem and relationship satisfaction may have consequences for the lives of mothers, fathers, and their children. Both self-esteem and romantic relationship satisfaction have been associated with psychological adjustment (Dush \& Amato, 2005; Orth, Robins \& Widaman, 2012), positive parenting behavior (e.g., Aunola, Nurmi, Onatsu-Arvilommi, \& Pulkkinen, 1999; Kitzmann, 2000) and beneficial influence on child development (e.g., Davies \& Cummings, 1994; Grych \& Fincham, 1990; Jones \& Prinz, 2005). These findings stress the importance to study how selfesteem and relationship satisfaction develop across the transition to parenthood.

In the present study, we used five waves of longitudinal data from 84,711 mothers to examine the extent to which developmental trajectories of romantic relationship satisfaction and self-esteem are similar and interconnected before and after childbirth in first-, second-, third-, and fourth-time mothers. In addition, we examined a subgroup of 9,438 mothers who participated twice in the study during their first and their second pregnancy. By utilizing large samples and a mixed between- and within-subjects design, we were able, for the first time, to provide a fine-grained picture of how self-esteem and relationship quality co-develop in mothers before and after childbirth. Longitudinal research on the development of self-esteem and relationship satisfaction has mostly focused on these domains separately. These two influential 
lines of literature give important information on how both constructs presumably change during the transition to motherhood. Below, we turn to the longitudinal literature on the development of self-esteem and relationship satisfaction over the lifespan and during the transition to parenthood. Subsequently, we describe how these constructs may be interconnected over time. Finally, we explain how our study on motherhood contributes to previous research on parenthood, self-esteem, and social relationships.

\section{Self-esteem Change across Adulthood}

Self-esteem is a relatively stable trait that yet undergoes systematic developmental changes throughout the lifespan (for reviews, see Orth \& Robins, 2014; Robins \& Trzesniewski, 2005). Various theoretical perspectives suggest that life events and the transition to parenthood in particular may be associated with changes in self-esteem. Some accounts emphasize the role of biological influences on self-esteem and focus on the physiological and neurological changes that are associated with the transition to motherhood. For example, a mothers' body image may be affected by the physical changes during pregnancy. These body image issues may in turn impact mothers' self-esteem (e.g., Robins \& Trzesniewski, 2005; Tiggeman, 2004).

Other theoretical perspectives consider motherhood as an opportunity to experience a sense of mastery and meaning (Mercer, 2004; Rubin, 1984). In particular, mastering the demands and challenges associated with motherhood may convey a sense of control over the self and the environment which may lead to increases in mothers' self-esteem (Robins \& Trzesniewski, 2005; Erol \& Orth, 2011). In summary, theory and previous research suggest that the transition to motherhood is an important period for the development of self-esteem in adulthood. Notably, the aforementioned processes are not mutually exclusive and might impact mothers' self-esteem at different times (i.e., during pregnancy and after birth) and in different ways. Also, compared to 
the birth of a first child, the birth of a second or third child may come with different challenges and changes. Evidence about the timing, direction, and generalizability of self-esteem change across first-, second- or multiple-time mothers is needed to gain insights about the ways in which the transition to motherhood impact self-esteem development.

A handful of studies have looked into self-esteem change during major life transitions. These studies have found that changes in self-esteem are related to transitions in the domains of education (Chung et al., 2014), romantic relationships (Wagner, Becker, Lüdtke, \& Trautwein, 2015; Wagner, Lüdtke, Jonkmann, \& Trautwein, 2013; Lehnart, Neyer, \& Eccles, 2010), and parenthood (Bleidorn, Buyukcan-Tetik et al., 2016; Chen, Enright, \& Tung, 2015).

The two studies that have focused on self-esteem change during the transition to parenthood compared first-time parents to people without children (Bleidorn, Buyukcan-Tetik, et al., 2016; Chen et al., 2015). Chen et al. (2015) examined self-esteem change in a sample of young adults in which they not only examined main effects of age and parenthood status (i.e. being a parent or not) on self-esteem change, but also the interaction between age and parenthood status. They found that being a parent was negatively related to self-esteem. However, parenthood status interacted positively with age in predicting self-esteem, suggesting that individuals with children show more age-related increases self-esteem compared to individuals without children (Chen et al., 2015). In line with perspectives that emphasize that parenthood can lead to feelings for mastery and meaning (Mercer, 2004; Rubin, 1984), the authors speculated that after adapting to the challenges of having a newborn baby, cumulative parenting experience might eventually lead to increases in self-esteem (Chen et al., 2015). Bleidorn, Buyukcan-Tetik and colleagues (2016) also compared self-esteem change in new parents to self-esteem change in couples without children. This study found sudden declines 
in self-esteem in the year after childbirth and gradual decreases in the following three years after. In contrast, the comparison group did not show changes in self-esteem across the research period. These results suggest that the negative impact of the transition on self-esteem change might last at least until three years after childbirth.

Chen et al. (2015) and Bleidorn, Buyukcan-Tetik, et al. (2016) further examined the role of potential moderator variables, including parents' gender, age, and relationship status. Both studies found that decreases in self-esteem were more pronounced in mothers compared to fathers. In addition, Chen et al. (2015) found that the impact of the transition was moderated by parents' age, relationship status, and living arrangements. Specifically, the decline in self-esteem was steeper for parents who were younger and did not live together with their child or partner at childbirth. In sum, the results of these studies suggest that parenthood can trigger changes in selfesteem, that these changes were mostly negative, and particularly pronounced in new mothers.

\section{Relationship Satisfaction Change across Adulthood}

In contrast to self-esteem, only a few studies have examined the development of romantic relationship satisfaction across the lifespan (e.g., Vanlaningham, Johnson, Amato 2001; Umberson, Williams, Powers, Chen, Campbell, 2005). Theories of lifespan change in relationship satisfaction have emphasized the impact of changes in family roles and structures (Holman et al., 2001; Rodgers \& White, 1993; Vanlaningham, et al., 2001). Specifically, life transitions that involve an addition (e.g., childbirth) or subtraction (e.g., grown-up children leaving the home) of a family member have been theorized to cause changes in relationship satisfaction.

Presumably, the birth of the first child presents one of the most impactful stressors that may impact couples' relationship satisfaction, because it entails a large reorganisation of the 
family system (Belsky, Spanier, \& Rovine, 1983; Cowan \& Cowan, 1992/2000; LeMasters, 1957). Such changes might already start before the birth of the first child. When couples are preparing for the arrival of a baby, they mostly experience high levels of closeness and cohesion, which has often been referred to as the "honeymoon effect" (Doss et al., 2009; Feeney, Hohaus, Noller, Alexander, 2001). This honeymoon effect may cause temporary increases in relationship satisfaction before childbirth. Such pre-birth changes might be at least partly offset due to changes and challenges after the birth of a child. In particular, in addition to the reorganisation of the intimate relationship between partners, the transition to parenthood often entails changes in partners' work and family roles, such as a redivision of labor and household tasks (Sanchez \& Thomson 1997). Such changes present couples with new stressors and often introduce conflict between partners which then lead to declines in their romantic relationship satisfaction (Doss et al., 2009).

A large body of research provides evidence that the transition to parenthood triggers changes in romantic relationship satisfaction (for meta-analyses see, Mitnick, Heyman, \& Smith Slep, 2009; Twenge, Campbell, \& Foster, 2003). These studies have found high levels of marital satisfaction during pregnancy, followed by sudden declines directly after the birth of the first child and small to medium gradual declines in the following years. Several studies have shown that this decline in relationship satisfaction is stronger in new parents compared to couples without children (Don \& Mickelson, 2014; Doss et al., 2009; Grote \& Clark, 2001; Keizer \& Schenk, 2012; Lawrence, Rothman, Cobb, Rothman, \& Bradbury, 2008). In line with the aforementioned theories on the impact of family roles and structures, some evidence suggests that the decline in relationship satisfaction after childbirth may be related to changes in new parents' work, routines, and social lives. For example, in one study, new parents' relationship 
satisfaction correlated negatively with the decline in time they spent on joint leisure activities (Claxton \& Perry-Jenkins, 2008), and in another study, the decline in relationship satisfaction was especially strong in mothers who stopped working when they had their first child (Keizer, Dykstra \& Poortman, 2010).

The decline in relationship satisfaction during the transition to parenthood appears to hold for both men and women (Mitnick et al., 2009). However, some studies suggested that the sudden impact of the birth of the first child was especially pronounced in mothers (Twenge et al., 2003). Mothers seem to show sudden declines in relationship satisfaction directly after birth, whereas fathers tend to show more gradual declines that start a few months after childbirth (e.g., Grote \& Clark, 2001). This gender difference might be related to changes in couples' gender-role attitudes which seem to become more traditional after the transition to parenthood (Katz-Wise, Priess, \& Hyde, 2010). Such shifts to more traditional gender roles (i.e., the mother as primary caregiver, the father as breadwinner) after childbirth may cause more changes in the daily routines of women compared to men (Sanchez \& Thomson, 1997). Consistent with this hypothesis, previous research has shown that new mothers often experience conflicts with their partners over father involvement and the new division of tasks (Leventhal-Belfer, Cowan \& Cowan, 1992; Moller, Hwang \& Wickberg, 2008), which may negatively impact their romantic relationship satisfaction.

In addition to gender differences, several other factors have been found to strengthen or buffer the negative impact of the transition to parenthood on parents' relationship satisfaction (Doss \& Rhoades, 2017). For example, two meta-analyses have found that the impact of parenthood was more negative for parents who were from high socioeconomic groups, younger, or in shorter relationships (Mitnick et al., 2009; Twenge, et al., 2003). Other studies have found a 
stronger negative impact of the transition to parenthood on relationship quality for unplanned versus planned pregnancies (e.g., Cox, Paley, Burchinal, \& Payne, 1999), if the newborn was female (Cox, et al., 1999), or if the child had a difficult temperament (Wright, Henggeler, \& Craig, 1986). Taken together, existing research shows that the transition to parenthood triggers a decline in relationship satisfaction, which is especially strong in women and is moderated by individual and parenthood-related factors.

\section{The Interplay between Self-Esteem and Relationship Satisfaction}

To date, research on the transition to parenthood has either focused on changes in selfesteem or on changes in relationship satisfaction. However, according to the dynamic transactional perspective, changes in self-esteem and social relationships likely go hand in hand via continuous reciprocal transactions (Magnusson, 1990).

The self-esteem literature offers explanations on how and why transactions between selfesteem and romantic relationship satisfaction may unfold during the transition to parenthood. All major self-esteem theories, such as sociometer theory (Leary \& Baumeister, 2000; Leary, Tambor, Terdal, \& Downs, 1995), terror management theory (Greenberg, Solomon, Pysziynski, 1997) and self-broadcasting theory (Srivastava \& Beer, 2005) emphasize the links between selfesteem and social acceptance and belonging. For example, sociometer theory posits that selfesteem functions as a subjective monitor of someone's value within close relationships, social groups, and society as a whole (Leary \& Baumeister, 2000). According to sociometer theory, successful and satisfying romantic relationships increase individuals' feelings of belonging and social inclusion, and should therefore be associated with the maintenance and increase of selfesteem (Leary \& Baumeister, 2000). 
A few longitudinal studies provided support for the association between self-esteem and romantic relationship satisfaction over time. For example, a longitudinal study of romantic partners showed that relationship satisfaction predicted self-esteem two years later, while selfesteem did not predict relationship satisfaction (Schaffhuser, Wagner, Ludtke, \& Allemand, 2014). In two other studies that used five waves of data spread over 12-years (Orth et al., 2012) and two waves of data with a four-year time interval (Neyer \& Asendorpf, 2001), self-esteem predicted change in relationship quality, whereas relationship quality did not predict change in self-esteem in young adulthood. In addition, Mund, Finn, Hagemeyer, and Zimmermann (2015) found that self-esteem and relationship satisfaction were dynamically intertwined in two multiwave longitudinal datasets of adults. Within the first dataset consisting of young adults that were followed for 15 years across four waves, change in self-esteem and change relationship satisfaction were positively linked across all assessments. Within the second dataset consisting of a larger group of adults who reported on self-esteem and relationship satisfaction at three annual measurement waves, self-esteem and relationship quality were linked in the same manner.

Taken together, previous longitudinal studies have shown that self-esteem and relationship satisfaction are longitudinally intertwined. However, these studies were not able to control for external factors that might cause changes in both self-esteem and relationship satisfaction. For example, changes or adjustments in romantic relationships and self-esteem typically occur in the context of major life transitions (Lang et al., 2006). Examining if a specific life-transition influences self-esteem and relationship satisfaction in a similar way would provide new insights on the possible mechanisms underlying personality-relationship transactions.

In the current study, we focused on the transition to motherhood, which likely activates changes in self-esteem and the romantic relationship. As discussed in the previous sections, 
various changes and challenges associated with pregnancy and childbirth may impact mothers' self-esteem and relationship satisfaction. Some of these challenges have a stronger theoretical link with self-esteem (e.g., body image changes) whereas other challenges may be more strongly related to relationship satisfaction (e.g., redivision of household tasks).

Furthermore, some challenges of motherhood may influence self-esteem and relationship satisfaction in a similar fashion. For example, sleep deprivation and other immediate stressors associated with a newborn may lead to short-term decreases in both self-esteem and relationship quality. To the extent that common features of the transition to motherhood affect mothers' selfesteem and relationship satisfaction in the same manner, they should be associated with similar and potentially correlated changes in these constructs.

\section{Extending Previous Research}

As described in the previous section, we aimed to contribute to previous research on selfesteem and social relationships by focusing on the (co-)development of self-esteem and relationship satisfaction during the transition to motherhood. To provide a rigorous examination of these transactions, we extended previous research on change during life transitions with regard to three important issues concerning the sample characteristics, research design, and statistical modeling techniques.

First, to adequately study variability and change during life transitions, it is important that the time intervals between the assessment waves are appropriate for the particular transition and the expected rate of change (Bleidorn, 2015; Bleidorn, Hopwood, et al., 2016; Doss et al., 2009; Hertzog \& Nesselroade, 2003; Luhmann, Orth, Specht, Kandler, \& Lucas, 2014). Previous research on the impact of life transitions on personality or relationship change has often compared change in participants who experienced a particular life transition with change in 
participants who did not experience the transition during the study period. The majority of these studies employed two-wave longitudinal designs with varying time intervals between the two assessment waves (for a review, see Bleidorn, Hopwood, et al., 2016). These studies can provide important insights about the potential differences between individuals who experience life events versus individuals who do not. However, they are restricted in that they cannot provide information on when and how changes unfold during the different phases of a transition (Luhmann et al., 2014).

A second important and related issue concerns the statistical modeling of change before, during, and after a life transition. Piecewise growth models are a particularly useful approach to model different trajectories across different phases of a transition (Duncan, Duncan, \& Strycker, 2013). For each distinct phase, piecewise growth models require multiple measurement occasions to enable the estimation of the mean rate of change and the amount of variation in change between individuals. In addition, a useful feature of a piecewise growth model is that it allows estimating how covariates might differentially influence the measured constructs across these different phases (Duncan et al., 2013). For example, during the transition to motherhood, the months after childbirth can be seen as a unique phase that is distinct from pregnancy and the following years. This phase might be predicted by phase-specific influences, such as the child's development. In the current study, we used piecewise growth curve models to examine the direction and degree of change in self-esteem and relationship satisfaction during three phases of the transition to motherhood (i.e., during pregnancy, around childbirth, and after childbirth).

Third, another open question is whether the birth of the first child has different effects on change in self-esteem and relationship satisfaction compared to the birth of later children. Most previous longitudinal research on psychological changes during the transition to parenthood has 
focused on the birth of the first child (Twenge et al., 2003). One of the few studies on the impact of repeated life events studied changes in life satisfaction in response to experiencing divorce, marriage, and unemployment multiple times (Luhmann \& Eid, 2009). This study found that compared to experiencing the event the first time, the negative impact of divorce was less strong (adaptation), the impact of marriage was similar, and the negative impact of unemployment was stronger (sensitization) when the event happened repeatedly.

The three described patterns (adaptation, similar impact, and sensitization) might also be applied to other transitions that can be experienced multiple times, such as pregnancy and childbirth. Most theories of parenthood and psychological change have proposed adaptation patterns such that the birth of later children is less stressful and impactful, because parents are already familiar with the challenges of pregnancy, birth, and childrearing. By comparison, there are some reasons to suggest that the experience of later pregnancies and the birth of later children has similar elements as the birth of the first child, such as similar physical and hormonal changes during pregnancy, or even more impactful elements, such as increases in childrearing activities and responsibilities (O’Reilly, 2004).

To the best of our knowledge, no study to date has tested whether the parents' personality changes differently during the birth of the first child compared to the birth of a second or later child. Only a handful of longitudinal studies have compared the change in relationship satisfaction of first-time parents and experienced parents. The results of these studies mostly suggested similar declines in relationship satisfaction in both groups of parents (Belsky et al., 1983; Figueiredo \& Conde, 2015; Krieg, 2007; O’Brien \& Peyton, 2002; but see Wilkinson, 1995). However, these studies used relatively small sample sizes, and therefore had limited power to detect potential group differences. 
In the current study, we addressed these issues about sample characteristics, research design, and statistical modeling techniques simultaneously. By doing so, we provided an extensive test of the (co-)development of self-esteem and relationship satisfaction during the transition to motherhood and the transition to a family with subsequent children.

\section{The Present Study}

The present research used five waves of longitudinal data from more than 80,000 mothers who reported on their self-esteem and romantic relationship satisfaction from early pregnancy until 3 years postpartum. Specifically, we aimed to address three questions.

Our first question was whether and how relationship satisfaction and self-esteem (co-) develop before and after childbirth. The aforementioned theoretical perspectives may imply some differences in how mothers change in self-esteem and relationship satisfaction. However, two empirical studies on self-esteem during the transition to parenthood (Chen et al., 2015; Bleidorn, Buyukcan-Tetik, et al., 2016) suggest that mothers' self-esteem and relationship satisfaction show a somewhat similar trajectory. Therefore, we expected to observe a similar change pattern for both relationship satisfaction and self-esteem. That is, we expected increases during pregnancy, sudden declines directly after birth, followed by gradual decreases in the years following childbirth. Similar to previous studies by Doss et al. (2009) and Bleidorn, BuyukcanTetik, et al. (2016), we compared several linear and non-linear change models to test which one best captured the shape and direction of change during the different phases of the transition for self-esteem and relationship satisfaction (i.e., during pregnancy, around childbirth, after childbirth). These trajectories are shown in Figure 1, and are explained in more detail in the method section. Moreover, we predicted that changes in self-esteem and relationship satisfaction are positively correlated. Strong correlated change would indicate that mothers who increase in 
self-esteem also increase in relationship satisfaction, whereas mothers showing decreases in selfesteem would also decrease in relationship satisfaction. Examining correlated change is important for gaining greater insight into personality-relationship transactions (Hertzog \& Nesselroade, 2003).

Our second question was whether the developmental trajectories of relationship satisfaction and self-esteem of first-time mothers differ from those of mothers that experience their second, third, or fourth pregnancy. We predicted that the birth of the first child had a stronger impact on change in self-esteem and relationship satisfaction, compared to the birth of a second or later child (i.e., an adaptation effect). We compared first-time and experienced mothers in two ways: (1) by examining the trajectories of self-esteem and relationship satisfaction in four large samples of first-, second-, third-, and fourth-time mothers, (2) by examining the trajectories during and after the first and second pregnancy of mothers that participated twice.

Our third research question was to which degree other potentially relevant moderators may account for individual differences in change. Specifically, we focused on three broad categories of moderator variables that have been shown to be related to either self-esteem or relationship satisfaction: (a) individual-level covariates (mothers' age, education level, civil status and employment status), (b) pregnancy-related covariates (unplanned pregnancy, pre-term birth) and (c) post-birth covariates (child temperament, gender of the child).

\section{Method}

\section{Sample and Procedure}

Data came from the Norwegian Mother and Child Cohort Study or MoBa (den Norske Mor \& Barn-Unders $\varnothing$ kelsen), an ongoing longitudinal cohort study conducted by the Norwegian Institute of Public Health (Magnus et al., 2016). The establishment and data collection in MoBa 
has obtained a licence from the Norwegian Data Inspectorate. In addition, the MoBa study and the current sub-study (project number 1519) obtained approval from The Regional Committee for Medical Research Ethics. No other published papers using the MoBa dataset focused on (codevelopment of self-esteem and relationship satisfaction during the transition to motherhood (for an overview of all MoBa sub-studies, please see www.fhi.no/en/studies/moba/).

All pregnant women who underwent routine ultrasound checkups in Norway were invited to enroll in the study between 1999 and 2008. From all women who were invited, $41.0 \%$ agreed to participate (for more information about self-selection bias in MoBa, see Nilsen et al., 2009). Women were allowed to participate more than once (i.e., with more than one pregnancy). After giving consent, participants completed questionnaires at two time-points during pregnancy (T1 and $\mathrm{T} 2$, during the $18^{\text {th }}$ and $30^{\text {th }}$ week of pregnancy), and at three time-points after the birth of the child (T3, T4 and T5, when the child was 6 months, 18 months, and 36 months of age, respectively). Here we used data released by the Norwegian Institute of Public Health in February 2014 (version 8), which contained 84,711 mothers.

We initially focused on the first participation of this sample of 84,711 mothers $(M$ age $=$ 29.59 years, $S D=4.68$ years). At the time of pregnancy, the majority of these mothers $(60.5 \%)$ had completed university or college education. A major percentage of the participants were in paid employment $(90.1 \%)$ and married/co-habiting with their romantic partner $(96.3 \%)$ at the time of pregnancy. Approximately one out of five pregnancies was unplanned (19.5\%) and a minority of the sample gave birth before 37 weeks of gestation $(6.0 \%)$, which is the standard definition of pre-term birth.

We split this sample into four subsamples, based on whether mothers reported this pregnancy to be their first $(\mathrm{N}=45,488 ; M$ age $=28.04$ years, $S D=4.53$ years $)$, second $(\mathrm{N}=$ 
$25,524 ; M$ age $=30.47$ years, $S D=4.08$ years $)$, third $(N=11,211, M$ age $=34.72$ years, $S D=$ 3.88 years $)$ fourth or later pregnancy $(\mathrm{N}=2,488, M$ age $=32.72$ years, $S D=3.74$ years $)$. In a second step, we focused on those women who participated twice in the MoBa study, with their first and their second pregnancy. This sample consisted of 9,438 women ( $M$ age $=27.81$ years, $S D=3.89$ years). The descriptive statistics of all samples are included in Table 1 and Table 2.

\section{Measures}

Self-esteem. Self-esteem was measured using a 4-item version (Tambs, 2004) of the Rosenberg Self-esteem scale (Rosenberg, 1965), which has been shown to have good reliability and correlates strongly with the original 10-item version (Tambs \& Røysamb, 2014). Example items were: 'I feel completely useless at times' (reverse coded) and 'I have a positive attitude toward myself'. All items were answered on a 4-point Likert scale ranging from 'strongly disagree' to 'strongly agree'. In this sample, Cronbach's alpha ranged from .75 to .79 across measurement waves.

Relationship satisfaction. A 5-item scale originally developed in Norwegian and based on core items used in previously developed measures of marital satisfaction and relationship quality (e.g. Blum \& Mehrabian, 1999; Hendrick, 1988; Snyder, 1997) was used to measure mothers' relationship satisfaction with her partner (Røysamb, Vitters $\varnothing, \&$ Tambs, 2014). Example items were: 'My partner and I have problems in our relationship' (reverse coded) and 'I am very happy with our relationship'. Participants answered the items on a 6-point Likert scale ranging from 'strongly disagree' to 'strongly agree'. A high correlation (.91) of this scale with the Quality of Marriage index (Norton, 1983) supported convergent validity (Røysamb et al., 2014). In the current sample, Cronbach's alpha ranged from .85 to .90 across measurement waves. 
Individual-level Covariates. We included four individual-level variables as covariates, which were all measured at T1. The covariates were mothers' age (median-centered at 30 years), mothers' education level (transformed to z-scores), civil status $(0=$ unmarried/not co-habiting, 1 $=$ married/co-habiting $)$ and employment status $(0=$ no paid employment, $1=$ paid employment $)$.

Pregnancy-related Covariates. We examined the two pregnancy-related variables, both measured when the child was 6 months of age (T3). The first variable was unplanned pregnancy $(0=$ unplanned, $1=$ planned $)$; the second was pre-term birth, for which we used the standard definition of all livebirths at less than 37 weeks' gestation $(0=$ term birth, $1=$ pre-term birth $)$.

Post-birth Covariates. We included gender of the child $(0=$ boy $1=$ girl $)$ and difficult temperament as post-birth covariates. Both variables were measured at T3. Difficult temperament was measured using a 10-item scale that was based on the Infant Characteristics Questionnaire, which is a questionnaire developed to measure infant difficultness (Bates, Freeland, \& Lounsbury, 1979). Example items were 'The child cries and complains a lot' and 'The child is easy to handle' (reverse coded). All items were answered on a 7-point Likert scale ranging from 'completely disagree' to 'completely agree'. The items were averaged and transformed to z-scores. In the current sample, Cronbach's alpha was .71.

\section{Analyses}

Prior to our main analyses, we tested for strict measurement invariance across time for both self-esteem and relationship satisfaction using confirmatory factor analyses (Meredith, 1993). As can be seen in Table S1 in the supplemental materials, models that tested for strict measurement invariance across time fit the data well $(\mathrm{CFI}>.96$, RMSEA <.04). These results indicate that the constructs of self-esteem and relationship satisfaction have the same meaning 
during pregnancy as in the subsequent phases after birth. As a consequence, change over time can be meaningfully interpreted (see the online supplemental materials for details).

As a next step, we transformed self-esteem and relationship satisfaction to T-scores using the grand mean and standard deviation of the total sample. T-scores are standardized scores with a mean of 50 and a standard deviation of 10. Cohen (1988) classified a difference of 2 T-score points as a small effect, a difference of 5 points as a medium effect, and a difference of 8 points as a large effect.

We used structural equation modeling and full information maximum likelihood in Mplus Version 7 to test our hypotheses (Muthén \& Muthén, 1998-2012). Each model was based on a latent growth curve model using all five waves of data. For each model, we took into account the unequal time-intervals between the five assessments. Specifically, the time-intervals were 0.25 years between $\mathrm{T} 1$ and $\mathrm{T} 2,0.71$ years between $\mathrm{T} 2$ and $\mathrm{T} 3,1.01$ years between $\mathrm{T} 3$ and $\mathrm{T} 4$, and 1.52 years between T4 and T5. Adequate model fit was indicated by the root mean square error of approximation $(\mathrm{RMSEA})<.08$, comparative fit index $(\mathrm{CFI})>.90$ and Tucker-Lewiss fit index $(\mathrm{TLI})>.90(\mathrm{Hu} \&$ Bentler, 1998).

Unconditional piecewise growth curve model. We first tested which change-pattern had the best fit to the data separately for self-esteem and relationship satisfaction. The selection of change models was guided by previous longitudinal research on the transition to parenthood (Doss et al., 2009; Bleidorn, Buyukcan-Tetik, et al, 2016). In doing so, we were able to replicate and extend previous research that has found both sudden and gradual changes in self-esteem and relationship quality before, during, and after the birth of a child. Specifically, we estimated eight different models (Figure 1) and tested which model fit the data best based on Bayesian Information Criteria (BIC) values. First, we tested which of the eight models fit best for the 
complete dataset, then we tested which model best described the change in each of the four subsamples of mothers expecting their first or later child. We repeated these analyses within the group of mothers who had participated with two pregnancies.

The first two models tested if single-phase latent growth curve models fit the data. The first model (1a) was an intercept-only model, in which a latent intercept was estimated. In Model $2 \mathrm{a}$, both a latent intercept and linear latent slope were estimated. Model 1a and 2a would indicate that mothers' self-esteem or relationship satisfaction were not associated with the birth of the child.

In the remaining six models, we subdivided change into three phases (i.e., during pregnancy, around childbirth, after childbirth) by using piecewise growth curve models (Duncan et al., 2013; Kim \& Kim, 2012). This was done by estimating one intercept centered at the first measurement occasion, and three change processes (i.e., three linear slopes). The three slopes reflected change during pregnancy, around childbirth and after childbirth. All of these models would indicate an effect of the transition to parenthood on self-esteem and relationship quality, respectively. Specifically, Model $1 \mathrm{~b}$ and $2 \mathrm{~b}$ would indicate linear change (increase or decrease) around childbirth, and no differences in the change-pattern during pregnancy and after childbirth. This sudden change in self-esteem or relationship satisfaction around childbirth would indicate a direct effect of childbirth. Model 1c, 2c, $1 \mathrm{~d}$ and $2 \mathrm{~d}$ reflect different patterns of change during each of the three phases of the transition. Based on previous research, we expected that Model $2 \mathrm{~d}$ would fit best for both relationship satisfaction and self-esteem for first-time mothers.

With only two pre-birth assessments it was necessary to fix the variance of the first slope (i.e., during pregnancy) in all piecewise models (i.e., Model 1b, 2b, 1c, 2c, 1d, and 2d) to allow model identification. To ensure that a better model fit was not due to freeing or fixing the slope 
variance, we first fixed all slope-variances and covariances to zero in all eight models. In this way, a lower BIC value would indicate a better fit of the average change trajectory to the data. After choosing the best-fitting average trajectory, we further examined if freeing the variance of the second and third slope improved model fit using model comparison tests.

Parallel process piecewise growth curve model. To examine how self-esteem and relationship satisfaction co-develop, we combined the best-fitting models of both constructs in a multivariate model and allowed the intercepts and slopes to correlate with each other (Figure 2). The manifest variables of self-esteem and relationship satisfaction were allowed to correlate at every assessment wave. Co-development would be indicated by correlated changes between the slopes of self-esteem and relationship satisfaction.

Differences between first and later pregnancies. After establishing the best-fitting model for the complete sample, we tested which of the theoretical models fit best for self-esteem and relationship satisfaction in each of the four subgroups separately (first, second, third, fourth or later pregnancy). To further test how first-time mothers differed from mothers expecting a subsequent child, we used a multi-group model. In this model, we combined the groups of mothers expecting their second, third, fourth or later child into one group. We used Wald tests to examine if initial levels and slopes of self-esteem and relationship satisfaction of first-time mothers differed from mothers expecting a subsequent child.

We repeated these analyses within the group of mothers who had participated with two pregnancies in the study to examine which change model fit best for the birth of their first and second child, and used Wald tests to examine if the initial level and change in self-esteem and relationship satisfaction differed between their first and second pregnancy. 
Conditional piecewise growth model. To examine the moderating effects of individuallevel variables, pregnancy-related variables and post-birth variables, we included these three categories of covariates to the piecewise growth curve models. Specifically, for both self-esteem and relationship satisfaction, we estimated three conditional piecewise growth models in which the impact of the covariates on the intercept and slopes was analyzed.

\section{Results}

All analyses were based on all available responses of mothers who completed at least one of the five assessment waves. At the first time-point $\left(\mathrm{T} 1,18^{\text {th }}\right.$ week of pregnancy), response rates were $99.3 \%$ for self-esteem and $97.4 \%$ for relationship satisfaction. At the second time-point (T2, $30^{\text {th }}$ week of pregnancy), response rates were $90.4 \%$ for self-esteem and $90.0 \%$ for relationship satisfaction. After birth, response rates dropped to $84.6 \%$ and $83.0 \%$ at the third time-point (T3, when the child was 6 months old), $69.2 \%$ and $68.3 \%$ at time-point 4 (T4, 18 months) and 51.7\% and 51.4\% at time-point 5 (T5, 36 months) for self-esteem and relationship satisfaction respectively. Compared to participants who completed all five assessments, participants with (partly) missing responses after the first time-point were slightly younger ( $d=$ $0.13)$, and had slightly lower levels of self-esteem $(d=-0.14)$ and relationship satisfaction $(d=-$ 0.17 ) at $\mathrm{T} 1 .^{1}$ Thus, our results may be slightly biased towards mothers who are older and who exhibit higher self-esteem and relationship satisfaction.

\section{Unconditional Piecewise Growth Curve Models}

Separately for self-esteem and relationship satisfaction, we first examined which of the eight change models best described the average trajectories in the complete sample. Based on

\footnotetext{
${ }^{1}$ In addition to the complete sample consisting of all participants, we selected a subsample of participants $(N=$ 36,638) who completed all questionnaires. Between the complete sample and the subsample, we compared the change trajectories for self-esteem and relationship satisfaction, and found that the trajectories were practically identical. Therefore, we used the complete sample for further analysis.
} 
BIC values, Model $2 \mathrm{~d}$ had the best fit for both self-esteem and relationship satisfaction (Table 3).

The mean-level pattern in the raw data (Table 1) also indicated a three-piece model with different pieces before, around, and after childbirth, further supporting our analytic strategy. For both constructs, freeing the variance of the second and third slope significantly improved the model fit. ${ }^{2}$ The final models had a good fit for both self-esteem $($ RMSEA $=0.005$, CFI $=1.000$, $\mathrm{TLI}=1.000)$ and relationship satisfaction $(\mathrm{RMSEA}=0.018, \mathrm{CFI}=0.999, \mathrm{TLI}=0.998)$.

The parameter estimates indicated that self-esteem decreased during pregnancy (-6.49 Tscores per year), followed by an increase around childbirth (2.48 T-scores per year) and a gradual decrease in the following years after (-0.60 T-scores per year; Table 4). Relationship satisfaction showed a small increase during pregnancy (1.98 T-scores per year), followed by a decrease around childbirth (-2.28 T-scores per year), and a gradual decrease in the years following childbirth (-1.08 T-scores per year). The variances around the second and third slope were significant for self-esteem and relationship satisfaction, indicating that mothers showed significant individual differences in change.

\section{Parallel Process Piecewise Growth Curve Model}

To test for correlated change, we combined the best-fitting model (Model 2d) for selfesteem and relationship satisfaction in a bivariate piecewise growth curve model (Figure 2). This model had a good fit $(\mathrm{RMSEA}=0.009, \mathrm{CFI}=1.000, \mathrm{TLI}=0.999)$. Because the variances of the linear slopes during pregnancy were fixed (see Footnote 2), they could not be correlated. The initial levels of self-esteem and relationship satisfaction showed a significant positive correlation $(\mathrm{r}=.40)$. Furthermore, we found evidence for correlated change, as changes in self-esteem were

\footnotetext{
${ }^{2}$ The variance of the first slope as well as its covariance with the other latent variables (i.e., the intercept, second slope, and third slope) had to remain fixed to zero to allow model estimation. That is, without fixing the variance of the first slope, the model would have more estimated parameters than data points (i.e., 21 parameters with only 20 pieces of known information) and would therefore not be identified.
} 
significantly positively correlated with changes in relationship satisfaction, both around $(\mathrm{r}=.39)$ and after $(\mathrm{r}=.34)$ childbirth (Table 5).

\section{Comparing First and Later Pregnancies between Mothers}

To examine if the change-trajectories of self-esteem and relationship satisfaction differed between first, second, third and fourth-time mothers, we first tested which of the eight models fit best for each of these four subgroups separately. Additionally, we combined the best-fitting models in a multi-group model to test if the change-trajectories of first-time mothers differed significantly from the change-trajectories of mothers expecting subsequent children.

Self-Esteem. For self-esteem, the best-fitting model was Model $2 \mathrm{~d}$ for all four subgroups. Table S2 and S5 in the supplemental materials show the BIC values and parameter estimates. Freeing the variance of the second and third slope further improved the model fit of all models. The model estimates indicated that all groups showed a similar change-trajectory. Specifically, all groups decreased in self-esteem during pregnancy, increased around childbirth and showed a gradual decrease in the years after childbirth (Figure 3). The final models for self-esteem showed good fit across subgroups (RMSEA $<0.020$, CFI $\geq 0.999$, TLI $\geq 0.999$ ).

For a more formal test of the hypothesis that the first child would have the largest impact on self-esteem compared to the birth of subsequent children, we used a multi-group model in which we combined the groups of mothers expecting their second, third, fourth or later child into one group. We tested if initial levels and slopes of self-esteem of this combined group differed from first-time mothers using Wald tests. Small but significant differences in self-esteem were found between first-time mothers and mothers that expected a subsequent child. Specifically, compared to mothers expecting a later child, first-time mothers had significantly higher initial levels of self-esteem $($ Wald $=82.53, \mathrm{p}<.001)$, an attenuated decline during pregnancy $($ Wald $=$ 
$10.85, \mathrm{p}=.001)$, a steeper increase around childbirth $($ Wald $=7.12, \mathrm{p}=.007)$ and a greater decrease after childbirth (Wald $=7.79, \mathrm{p}=.005)$. In general, although all differences in change were significant, these differences were very small in terms of effect sizes (less than $1 \mathrm{~T}$-score, see Table S5), which indicated that the self-esteem levels and trajectories of the four subgroups were roughly similar.

Relationship Satisfaction. For relationship satisfaction, the best-fitting model was Model $2 \mathrm{~d}$ for first and second-time mothers. The BIC values and parameter estimates can be found in Table S3 and S6 in the supplemental materials. For mothers experiencing their third, fourth or later pregnancy, Model 1c was the best-fitting model. We again freed the variance of the second and third slope to improve model fit. For first pregnancies, the trajectory started with a small increase in relationship satisfaction during pregnancy, followed by a decrease that was strongest around childbirth, compared to the more gradual decrease in the years after childbirth. Although Model 2d was the best-fitting model for second-time mothers, the trajectory of relationship satisfaction in this group looked similar to the trajectory of third and fourth-time mothers. Specifically, these three subgroups all showed a small increase during pregnancy, followed by a gradual linear decrease around birth and in the years after birth (Figure 4). The models for relationship satisfaction showed good fit across subgroups (RMSEA $<0.024$, CFI $\geq$ 0.998, TLI $\geq 0.997)$.

We again used a multi-group model to test how the initial level and slope of romantic relationship satisfaction differed between first-time mothers and mothers expecting subsequent children. First-time mothers had significantly higher initial levels of relationship satisfaction (more than 3 T-scores; Wald $=2808.62, p<.001$ ). No differences in change were found during pregnancy $($ Wald $=0.60, p=0.438)$. In addition, first-time mothers showed a steeper decline in 
relationship satisfaction around (Wald $=638.65, p<.001$ ) and after childbirth (Wald $=100.79, p$ $<.001$ ). In terms of effect sizes, these differences in change were small around childbirth (around $2 \mathrm{~T}$-scores) and very small after childbirth (less than $1 \mathrm{~T}$-score).

\section{Comparing the First and Second Pregnancy within Mothers}

In addition to comparing the differences between the four subgroups, we also tested which of the eight models fit best for mothers who participated twice (i.e., with their first and second pregnancy). Below, we compared the first and second pregnancy of this group of mothers for self-esteem and relationship satisfaction separately.

Self-esteem. The BIC values and parameter estimates can be found in Table S4 and S5 in the supplemental materials. The results of these analyses largely resembled the results of the comparison between the four subgroups. For both the first and second pregnancy, Model $2 \mathrm{~d}$ fit best for self-esteem, indicating a linear decrease during pregnancy, an increase around childbirth and a linear decrease in the years after childbirth (Figure 5). We again freed the variance of the second and third slope, and the final models showed good fit $(\mathrm{RMSEA}<0.007, \mathrm{CFI}=1.000$, $\mathrm{TLI}=1.000)$.

We used Wald tests to examine if the intercepts and slopes differed significantly between the first and second pregnancy. We found that the mothers did not differ in their initial levels of self-esteem during their first pregnancy compared to their second pregnancy (Wald $=0.46, p=$ .497). We did find differences in change during pregnancy, in that the decline in self-esteem during the first pregnancy was stronger compared to the decline during the second pregnancy (Wald $=11.97, p<.001)$. In the phase around childbirth, women showed a stronger increase in self-esteem the first time they became mothers compared to the second time (Wald $=42.80, p$ <.001). In the years after childbirth, women showed no differences in self-esteem change after 
their first and second pregnancies (Wald $=0.19, p=.660$ ). The differences in initial level and change between the first and second pregnancy were small (less than $2 \mathrm{~T}$-scores) indicating that the degree and direction of change was similar across the first and second pregnancy.

Relationship satisfaction. Similar to the results of the comparison between the four subgroups, we found that Model 2d fit best for relationship satisfaction for both the first and second pregnancy (see Table S4 and S6 in the supplemental materials). During both pregnancies, relationship satisfaction showed a small increase. This was followed by a decrease that was strongest around childbirth, compared to the more a gradual decrease in the years after childbirth (Figure 6). Model fit improved after freeing the variance of the second and third slope. The final models for relationship satisfaction showed good fit to the data (RMSEA $\leq 0.024$, CFI $\geq 0.999$, $\mathrm{TLI} \geq 0.997)$.

We again used Wald tests for significant differences between the first and second pregnancy. We found that mothers had significantly higher initial levels of relationship satisfaction during the first pregnancy compared to the second pregnancy (more than 3 T-scores, Wald $=1514.46, p<.001)$. In addition, we also found significant differences in change between the first and second pregnancy. The first time the women became mothers, they showed a slightly stronger increase during pregnancy (Wald $=6.15, p=.013$ ) and a steeper decrease around childbirth $($ Wald $=23.06, p<.001)$ and in the years after childbirth $($ Wald $=69.10, p<$ .001). These significant differences in change were very small (less than $1 \mathrm{~T}$-score), indicating that the changes in relationship satisfaction were similar within this group of mothers during their first and second pregnancy.

\section{Conditional Piecewise Growth Curve Models}


The results of the conditional piecewise growth model are shown in Table 6 for selfesteem and in Table 7 for relationship satisfaction. The very large sample size allowed us to accurately detect very small effects that were statistically significant, but might not have meaningful implications. Therefore, we only focused on effects that were larger than $1 \mathrm{~T}$-score.

Individual-level covariates. In a first set of analyses, we included all individual-level variables as predictors of self-esteem and relationship satisfaction. This model indicated that initial levels of self-esteem were more than $9 \mathrm{~T}$-scores higher for mothers who were married or co-habiting with their romantic partner. Additionally, mothers who were married/co-habiting showed a less steep increase (around $1 \mathrm{~T}$-score) in self-esteem around birth, compared to mothers who were not married/co-habiting. All other individual-level variables (i.e., age, education level, paid employment) showed only small (less than $1 \mathrm{~T}$-score) effects on the initial level and change in self-esteem (see Table 6).

For relationship satisfaction, results indicated significantly higher initial levels for mothers who were higher educated (effect around 1 T-score). In addition, higher initial levels were found in mothers who were in paid employment and married/co-habiting, with both variables showing an effect size of more than $2 \mathrm{~T}$-scores. The slopes of relationship satisfaction did not show strong associations with any of the individual-level variables (i.e., less than $1 \mathrm{~T}$ score difference).

Pregnancy-related covariates. In a second set of analyses, we examined the moderating effects of pregnancy-related variables. The results indicated that the initial level of self-esteem was more than 3 T-scores higher when the pregnancy was planned. Planned pregnancy only showed very small associations with change in self-esteem (less than 1 T-score). All associations between pre-term birth and self-esteem showed a very small effect size of less than $1 \mathrm{~T}$-score. 
Similar to self-esteem, initial levels of relationship satisfaction were also positively associated with planned pregnancy (effect around $2 \mathrm{~T}$-scores). All other associations between planned pregnancy/pre -term birth and relationship satisfaction were very small, with an effect size of less than $1 \mathrm{~T}$-score.

Post-birth covariates. In the third set of analysis, we examined the moderating effects of two post-birth variables; the child's gender and difficult temperament. Because the initial levels of self-esteem and relationship satisfaction were centered at T1 during pregnancy, we did not interpret the prediction of these levels by post-birth variables, and focused solely on how postbirth variables were associated with change in self-esteem in relationship satisfaction. Difficult temperament was negatively associated with change in self-esteem around childbirth (effect size around $1 \mathrm{~T}$-score). The association between difficult temperament and change in relationship satisfaction had a very small effect size of less than $1 \mathrm{~T}$-score. Additionally, gender of the child did not predict change in self-esteem and relationship satisfaction.

\section{Discussion}

In the current study, we examined mothers' trajectories of self-esteem and romantic relationship satisfaction during pregnancy, around childbirth, and after childbirth. To gain insight into transactions between self-esteem and relationship satisfaction, we examined if and how these trajectories were similar and interconnected. In addition, we tested if these trajectories were different for first-time mothers compared to mothers that experienced their second, third, or fourth pregnancy and to which degree moderators explained individual differences in change. Combining rigorous model-testing strategies and piecewise growth models across a large sample of mothers, this study makes several important contributions to the literature on self-esteem, 
relationship satisfaction, and personality-relationship transactions. Below, we discuss the implications of the results with regard to our research questions.

\section{Trajectories of Change}

Our first question was whether and how relationship satisfaction and self-esteem (co-) develop before and after childbirth. The results from our piecewise growth models indicated that, although self-esteem and relationship quality showed similar gradual declines in the years after childbirth, these two constructs differed in change during pregnancy and around childbirth. Specifically, while self-esteem showed a strong decline during pregnancy, relationship quality remained relatively steady during this phase. Around childbirth, self-esteem increased until the child was six months old. In contrast, relationship satisfaction declined during this phase of the transition. These results suggest that pregnancy and childbirth trigger different mean-level changes in maternal self-esteem and relationship satisfaction. The differences and similarities in these mean-level change patterns are discussed in more detail in the following section, where the trajectories in first and later pregnancies are compared.

Results from the parallel piecewise growth model showed that, at the individual level, changes in these constructs were significantly correlated. That is, we found positive correlated change between these domains around childbirth and after childbirth. The positive correlated change indicated that mothers who increased in self-esteem also increased in relationship satisfaction, whereas mothers who showed decreases in self-esteem also decreased in relationship satisfaction. This correlated change could be caused by transactions between selfesteem and the romantic relationship, which is in line with the propositions of dynamic interactionism (Caspi \& Roberts, 2001; Magnusson, 1990, Neyer \& Asendorpf, 2001). In addition, correlated change might reflect that some aspects of this transition influenced self- 
esteem and relationship satisfaction in a similar fashion. Future studies comparing individuals in different life phases could explore if this correlated change is unique for individuals experiencing the transition to parenthood, or can be found in other contexts as well.

\section{Differences Between First and Later Pregnancies}

We further examined similarities and differences between self-esteem and relationship satisfaction by comparing first and later pregnancies. Our results indicated that the transition to motherhood and the transition to a family with subsequent children both triggered changes in self-esteem and relationship satisfaction. However, the proposition that the first child would have the strongest negative impact was only supported for relationship satisfaction. For self-esteem, change-trajectories for first-time mothers were highly similar to change trajectories of mothers expecting subsequent children.

Self-esteem. First-time mothers had slightly higher initial levels of self-esteem during pregnancy, compared to mothers that expected a subsequent child. However, the effect size of this difference was very small (i.e., less than $1 \mathrm{~T}$-score). Furthermore, we did not find a significant difference in initial level between the first and second pregnancy within mothers that participated twice.

A highly similar change-pattern was found for first-, second-, third- and fourth-time mothers, which was in contrast with our prediction that the birth of the first child would have the most pronounced effects on self-esteem. For all subgroups, self-esteem increased during pregnancy, dropped around childbirth and decreased gradually from six months until 3 years after childbirth. The gradual decline in the years after childbirth was in line with the results from the two previous studies on self-esteem during the transition to parenthood (Bleidorn, BuyukcanTetik, et al., 2016; Chen et al., 2015). 
Extending the results from these two studies, we distinguished between pregnancy and the phase around childbirth to determine when the decline in self-esteem started or was most pronounced. Contrary to our expectations, we found that self-esteem declined during pregnancy and increased until six months after birth. This self-esteem trajectory was not only replicated across the four subgroups, but also within women who participated with their first and second pregnancy.

The findings for self-esteem have at least two implications. First, the small differences in mean-levels of self-esteem across pregnancies indicated that having children did not trigger substantial long-term changes in maternal self-esteem. That is, in line with the study from Bleidorn, Buyukcan-Tetik, et al. (2016), we found gradual decreases until three years after childbirth. However, the self-esteem level of mothers that participated twice was similar during their first and second pregnancy, indicating that this gradual decline did not proceed over a timeinterval longer than three years. In addition, these findings did not support the idea that motherhood might eventually lead to increases in self-esteem (Chen et al., 2015), at least not over a period that included two pregnancies.

Second, the close replication of the self-esteem trajectory across the subsamples of mothers who had their first, second, third, or fourth child provides strong evidence that the observed change-pattern is normative during the transition to motherhood. These normative changes in self-esteem might be related to normative biological, social, and psychological changes that characterize pregnancy, childbirth, and early motherhood (e.g., physical and hormonal changes, labor, nursing).

For example, the seemingly normative dip in self-esteem around the $30^{\text {th }}$ week of pregnancy might be related to physical changes and changes in body image during that phase of 
pregnancy (Fox \& Yamaguchi, 2008). In addition, studies have shown that worries about the baby's development and giving birth increase during the third trimester of pregnancy (Statham, Green, Kafetsios, 1997; Öhman, Grunewald, Waldenström, 2003). Negative expectations about the future and a negative body image are also linked to low self-esteem (e.g. Alarcon, Bowling, \& Khazon, 2013; Tiggemann, 2004), suggesting that such worries and feelings during the third trimester of pregnancy might partly account for the declines in maternal self-esteem.

Relationship satisfaction. For relationship satisfaction, we found higher initial levels in first-time mothers compared to mothers expecting their second or later child. This was in line with results from previous research (e.g. Belsky et al., 1983; Figueiredo \& Conde, 2015). The observed change-pattern was also in line with previous research that showed that first-time mothers tend to experience the strongest declines in relationship satisfaction during the first six months after childbirth and less pronounced decreases in the following years after childbirth (Mitnick et al., 2009).

Our analysis of different subgroups of mothers revealed that mothers who expected their second, third, or fourth child experienced a less steep decline in relationship satisfaction around childbirth than first-time mothers. These results were similar to the findings from a previous study by Wilkinson et al. (1995), in which the decline in relationship satisfaction in the first three months after childbirth was strongest in first-time mothers compared to women who expected their second or later child.

Going beyond the comparison of different groups of mothers, we also compared the first and second pregnancy of mothers who participated twice. Similar to the comparison between different groups, we found that mothers who participated with two pregnancies experienced a higher level of relationship satisfaction during their first pregnancy compared to their second 
pregnancy. This might suggest that having children has more lasting negative effects on relationship satisfaction.

It is important to note, however, that even though we found stronger declines after the birth of the first child compared to the birth of the second child, the differences in change were very small within this group of mothers. Self-selection bias might play a role in explaining this small effect size. It is possible that women who chose to participate again in this study did so because of their positive experiences during the transition to motherhood, which might be also related to less strong declines in their relationship satisfaction. In contrast, women who experienced the transition to motherhood as more stressful and who struggled with more relationship problems might have chosen not to participate again when they were pregnant for the second time. Supporting this explanation, the present results showed that mothers who participated with their first and second pregnancy reported indeed less strong declines in their relationship satisfaction after the birth of their first child compared to mothers who only participated once.

The results of the current study are in line with previous research that has shown that the transition to parenthood has unique effects on romantic relationship satisfaction. Comparing first-time parents with people without children, previous studies have found that declines in romantic relationship satisfaction could be attributed to childbirth (Doss et al., 2009; Lawrence et al., 2008). Our results further indicate that the decline in relationship satisfaction in first-time parents is not only different from the decline in the decline in people without children, but also from change during the transition to a family with subsequent children.

The stronger negative impact of the birth of the first child on relationship satisfaction might be explained by the fact that the transition to parenthood requires the largest 
reorganization of the family system (Belsky et al., 1983; LeMasters, 1957) and the most profound changes in daily behavior of parents, compared to the birth of later children (Cowan \& Cowan, 1992/2000). Because mothers usually experience a larger increase in household tasks and responsibilities after birth of the first child compared to their romantic partner, mothers' dissatisfaction about the new household division of labor between partners is likely to trigger sudden declines romantic relationship satisfaction (Moller et al., 2008).

An alternative explanation for the negative impact of childbirth on relationship satisfaction might be that the sudden changes after birth of the first child represent a return to pre-pregnancy levels. Specifically, it has been argued that higher levels of relationship satisfaction during pregnancy might be partly caused by the "honeymoon effect" (Doss et al., 2009; Feeney et al., 2001). That is, the expectation of having a child for the first time could mark a high point in couples' relationship, which is accompanied by a temporary increase in relationship quality during pregnancy. In the current study, we only had information about selfesteem and relationship satisfaction from the $18^{\text {th }}$ week of pregnancy onwards. Consequently, we were not able to determine how levels before pregnancy were related to the changes during pregnancy and after childbirth. However, studies that followed married couples before they were pregnant also found that relationship satisfaction declined after the birth of the first child compared to pre-pregnancy levels (e.g., Lawrence et al., 2008). This suggests that in temporal increases in relationship quality during pregnancy cannot completely account for the relative decline in relationship satisfaction after childbirth.

The differences in the mean-level trajectories of self-esteem and relationship satisfaction highlight complex short-term and long-term effects of motherhood. The pattern found for relationship satisfaction can partly be described as a process of adaptation, as the short-term 
decline in relationship satisfaction was less strong after the birth of the second or later child compared to the birth of the first child. Despite this adaptation effect, the results showed that relationship satisfaction continued to decline across multiple pregnancies. This might indicate that the stresses of parenthood accumulate over time, which could be related to the increases in childrearing activities and responsibilities when subsequent children are born (O'Reilly, 2004). These findings are important in the light of the long-term consequences of romantic relationship satisfaction for the lives of parents and their children. The lasting declines in relationship satisfaction emphasize the importance to not only focus on which factors might buffer against the declines during the transition to parenthood (Doss \& Rhoades, 2017), but also after the birth of subsequent children.

Pregnancy and childbirth only seemed to have short-term effects on self-esteem, and experiencing these events multiple times did not lead to sensitization or adaptation (Luhmann \& Eid, 2009). This does not mean that these short-term changes in mothers' self-esteem are not important, as mothers' negative psychological adjustment during pregnancy and after childbirth could have major consequences for both the mother and the child. For example, mothers with low levels of self-esteem during pregnancy have a higher risk of delivering a pre-term baby (Jesse, Seaver, \& Wallace, 2003) and experiencing a postnatal depression (Jomeen, 2004).

The differences in the average trajectories might be due to different normative processes that influence self-esteem and relationship quality during the transition to motherhood. However, the moderate correlated change may indicate that certain mechanisms influence these constructs in a similar way (Klimstra, Bleidorn, Asendorpf, Van Aken, \& Denissen, 2013). Future research should further examine which biological, psychological, and social processes during the transition to parenthood may cause these differences and similarities in the trajectories of 
mothers' self-esteem and relationship satisfaction (Ross et al., 2004). For example, little is known about how normative hormonal changes during pregnancy and after childbirth, such as changes in oxytocin (Levine, Zagoory-Sharon, Feldman, Weller, 2007), relate to changes in selfesteem and relationship satisfaction. Future research would benefit from including both biological and psychological measures into longitudinal examinations of the transition to motherhood in order to provide a more complete picture of the ways in which biological and psychological changes may interact before, during, and after the birth of a child.

\section{Moderators of Change in Self-Esteem and Relationship Satisfaction}

In addition to the mean-level change trajectories, previous research has indicated that the transition to motherhood is a highly idiosyncratic experience that may influence new mothers' self-esteem and relationship quality in distinct ways. Therefore, we also examined whether individual-level, pregnancy-related, or post-birth related factors influenced the shape of changes in self-esteem and relationship satisfaction over the transition to motherhood. In general, most covariates had only small effects on the initial levels and growth trajectories of relationship satisfaction and self-esteem.

To the best of our knowledge, this was the first study to examine if and how a large number of individual difference factors could explain changes in self-esteem during the transition to parenthood. The largest effect on initial level of self-esteem was found for civil status. Specifically, self-esteem levels were around 9 T-scores higher if mothers were married/co-habiting, which is according to Cohen's classification a large effect and consistent with previous research on self-esteem in parents (Chen et al., 2015). Furthermore, the initial level of self-esteem was more than 3 T-scores higher when the pregnancy was planned. In addition, although the effect sizes were small, more positive self-esteem change around childbirth was 
associated with a less difficult child's temperament and being married or co-habiting. Contrary to the results from Chen et al. (2015), we did not find that age was strongly linked to self-esteem.

Similar to self-esteem, we found that a higher initial level of relationship satisfaction was related to planned pregnancy and being married or co-habiting with a romantic partner (effect size around $2 \mathrm{~T}$-scores). Higher initial levels of relationship satisfaction were also found in mothers who were in paid employment and in mothers who were higher educated (effect size around $1 \mathrm{~T}$-score). A somewhat surprising finding was the lack of substantial associations between the covariates and change in relationship satisfaction. This was in contrast with previous studies, which for example found that the negative impact of childbirth on relationship satisfaction was larger in case of unplanned pregnancies (e.g., Cox, et al., 1999).

Generally, even though we found some small effects of individual-level, pregnancyrelated, and post-birth related factors, most covariates did not strongly predict short-term (i.e., the first six months after birth) or longer-term (i.e., the following three years after birth) changes in maternal self-esteem and relationship satisfaction. Although we followed mothers over a relatively long period of more than three years, we might have found larger effects if the time before the $18^{\text {th }}$ month of pregnancy and the time after the child's third birthday were also included. For example, individual-level or pregnancy-related factors might already trigger changes before the first time-point (i.e., before pregnancy, or during the first months of pregnancy). In addition, the child's difficult temperament might have a stronger impact on change in self-esteem and relationship satisfaction over a time-interval longer than three years.

Future research is needed to better understand individual differences in the direction and degree of change in self-esteem and relationship satisfaction. For example, we did not capture the day-to-day parenting challenges and interactions in the current study. These daily 
experiences might elicit changes in behaviors and states, which could lead to long-term changes in self-esteem and romantic relationship satisfaction. By combining measurement burst designs (e.g., daily diaries) with longer-term designs, future research could study how day-to-day parenting experiences relate to changes in personality and relationship satisfaction (Wrzus \& Roberts, 2016).

\section{Limitations and Future Directions}

The current study has some important strengths. Because of the frequently and welltimed measurements before and after childbirth, we were able to use piecewise growth curve models to determine the normative change-patterns for self-esteem and relationship satisfaction during the transition to motherhood. By doing so, we provided a detailed picture of the change trajectories during pregnancy, just after childbirth, and in the following years. In addition, because of its large sample size, the present study is the first to provide a high-powered comparison of the change trajectories of first-time, second-time, third-time, and more experienced mothers.

Despite these strengths, the results of the present study should be considered in the light of some important limitations. First, even though we were able to analyze change over frequent assessments that were closely timed around the life event of interest, our design was still limited in that there were no assessments before pregnancy. Without such assessments, it is not possible to study potential anticipatory changes in self-esteem and relationship quality. For example, changes might already start when couples consider the possibility of having a baby. Relatedly, with only two pre-birth assessments, it was not possible to model individual differences in selfesteem and relationship quality change during pregnancy. As a consequence, these models did not allow us to test whether there was correlated change between these constructs during 
pregnancy. We encourage future research to include more assessments during or even before pregnancy to further examine changes in self-esteem and relationship satisfaction before childbirth.

A second limitation was that some of the sample's characteristics might limit the generalizability of the results. As in most large cohort studies, the relatively low enrollment in MoBa (41.0\% of all women who were contacted) might cause self-selection biases. In the group of women who agreed to participate in the study, women younger than 25 years and those living alone were underrepresented, compared to the total population of Norwegian mothers (Nilsen et al., 2009). In addition, it remains an open question if similar results can be found in mothers from other countries. For example, the family friendly policies in Norway (e.g., paid parental leave, job leave security, and affordable daycare; Kotsadam \& Finseraas, 2011) might buffer Norwegian mothers from declining in self-esteem and relationship satisfaction after childbirth. Thus, the decline in relationship satisfaction and self-esteem might be stronger in countries where it is more difficult to juggle motherhood and work life. Furthermore, fathers were not included in this study, and we could therefore not examine how their change-pattern is different from mothers. We encourage future research to test if the change-patterns for self-esteem and relationship satisfaction can be replicated in more diverse samples of mothers and fathers from different social, economic, and cultural backgrounds.

A third limitation is the lack of a comparison group of women that did not experience the transition to motherhood. Although we extensively examined differences between first and later pregnancies, we were not able to compare the trajectories of self-esteem and relationship satisfaction between mothers and women without children. This also prevented us to test if self- 
esteem and relationship satisfaction predicted the likelihood to enter into motherhood (cf. Van Scheppingen, Jackson, Specht, Hutteman, Denissen, \& Bleidorn, 2016).

A fourth related limitation concerns the exclusive use of self-report data from mothers. Including partner reports would allow researchers to use dyadic analyses to test the self-esteemrelationship transactions over the transition to parenthood within and between mothers and fathers (cf., Bleidorn, Buyukcan-Tetik, et al., 2016). Furthermore, including multi-method assessments of parenthood challenges (e.g., sampling hormone levels or observing parent-child interactions) might provide additional insights in which circumstances trigger changes in selfesteem and relationship satisfaction.

\section{Conclusion}

Using a unique sample of more than 80,000 participants and five waves of longitudinal data, our findings provide important information about the development of self-esteem and relationship satisfaction during pregnancy and after childbirth. Several key findings emerged from this study. First, having children seemed to only trigger long-term changes in mothers' relationship satisfaction, and not in mothers' self-esteem. Second, maternal self-esteem showed a highly similar change-pattern across pregnancies and subgroups. Specifically, self-esteem decreased during pregnancy, followed by an increase until the child was six months old, and a gradual decline in the following years after. This replication across first, second, third, and subsequent pregnancies gives a strong indication that this is a normative change-pattern, which might be related to factors that are similar for every pregnancy and childbirth. Third, for relationship satisfaction, the birth of the first child had the strongest impact compared to the birth of subsequent children. In first-time mothers, relationship satisfaction showed high levels during pregnancy, followed by a sudden decrease around childbirth and a gradual decrease in the 
following years. In mothers that gave birth to subsequent children, the decrease in relationship satisfaction after childbirth was more gradual and linear compared to the sudden decrease found in first-time mothers. These results indicate that the challenges after birth of the first child have unique negative effects on romantic relationship satisfaction. Fourth, the moderate correlated change both around and after childbirth showed that self-esteem and relationship satisfaction were positively linked during and after the transition to motherhood. In sum, our study provided a fine-grained picture of how maternal self-esteem and relationship satisfaction change during pregnancy and after childbirth. 


\section{References}

Alarcon, G. M., Bowling, N. A., \& Khazon, S. (2013). Great expectations: A meta-analytic examination of optimism and hope. Personality and Individual Differences, 54(7), 821827. doi:10.1016/j.paid.2012.12.004

Aunola, K., Nurmi, J. E., Onatsu-Arvilommi, T., \& Pulkkinen, L. (1999). The role of parents' self-esteem, mastery-orientation and social background in their parenting styles. Scandinavian Journal of Psychology, 40(4), 307-317. doi:10.1111/1467-9450.404131

Back, M. D., Baumert, A., Denissen, J. J. A., Hartung, F.-M., Penke, L., Schmukle, S. C., ... Wrzus, C. (2011). PERSOC: A unified framework for understanding the dynamic interplay of personality and social relationships. European Journal of Personality, 25(2), 90-107. doi:10.1002/per.811

Bates, J. E., Freeland, C. A. B., \& Lounsbury, M. L. (1979). Measurement of Infant Difficultness. Child Development, 50(3), 794-803. doi:10.1111/j.14678624.1979.tb02428

Belsky, J., \& Rovine, M. (1990). Q-Sort security and first-year nonmaternal care. New Directions for Child and Adolescent Development, 1990(49), 7-22. doi:10.1002/cd.23219904903

Belsky, J., Spanier, G. B., \& Rovine, M. (1983). Stability and Change in Marriage across the Transition to Parenthood. Journal of Marriage and the Family, 45(3), 567. doi: $10.2307 / 351661$

Bleidorn, W. (2015). What Accounts for Personality Maturation in Early Adulthood? Current Directions in Psychological Science, 24(3), 245-252. doi:10.1177/0963721414568662 
Bleidorn, W., Buyukcan-Tetik, A., Schwaba, T., van Scheppingen, M. A., Denissen, J. J. A., \& Finkenauer, C. (2016). Stability and Change in Self-Esteem During the Transition to Parenthood. Social Psychological and Personality Science, 7(6), 560-569. doi:10.1177/1948550616646428

Bleidorn, W., Hopwood, C. J., \& Lucas, R. E. (2016). Life Events and Personality Trait Change. Journal of Personality. Advance online publication. doi:10.1111/jopy.12286

Blum, J. S., \& Mehrabian, A. (1999). Personality and Temperament Correlates of Marital Satisfaction. Journal of Personality, 67(1), 93-125. doi:10.1111/1467-6494.00049

Caspi, A., \& Roberts, B. W. (2001). Personality Development Across the Life Course: The Argument for Change and Continuity. Psychological Inquiry, 12(2), 49-66. doi:10.1207/s15327965pli1202_01

Chen, E. Y.-J., Enright, R. D., \& Tung, E. Y.-L. (2016). The influence of family unions and parenthood transitions on self-development. Journal of Family Psychology, 30(3), 341352. doi:10.1037/fam0000154

Cheung, G. W., \& Rensvold, R. B. (2002). Evaluating goodness-of-fit indexes for testing measurement invariance. Structural equation modeling, 9(2), 233-255. doi:10.1207/s15328007sem0902_5

Chung, J. M., Robins, R. W., Trzesniewski, K. H., Noftle, E. E., Roberts, B. W., \& Widaman, K. F. (2014). Continuity and change in self-esteem during emerging adulthood. Journal of Personality and Social Psychology, 106(3), 469-483. doi:10.1037/a0035135

Claxton, A., \& Perry-Jenkins, M. (2008). No Fun Anymore: Leisure and Marital Quality Across the Transition to Parenthood. Journal of Marriage and Family, 70(1), 28-43. doi:10.1111/j.1741-3737.2007.00459.x 
Cohen, J. (1988). Statistical power analysis for the behavioral sciences (2nd ed.). Hillsdale, NJ: Erlbaum.

Cowan, C. P., \& Cowan, P. A. (2000). When partners become parents: The big life change for couples. Lawrence Erlbaum Associates Publishers. (Original work published 1992)

Cox, M. J., Paley, B., Burchinal, M., \& Payne, C. C. (1999). Marital Perceptions and Interactions Across the Transition to Parenthood. Journal of Marriage and the Family, 61(3), 611. doi: $10.2307 / 353564$

Davies, P. T., \& Cummings, E. M. (1994). Marital conflict and child adjustment: An emotional security hypothesis. Psychological bulletin, 116(3), 387. doi:10.1037/00332909.116.3.387

Denissen, J. J. A., Penke, L., Schmitt, D. P., \& van Aken, M. A. G. (2008). Self-esteem reactions to social interactions: Evidence for sociometer mechanisms across days, people, and nations. Journal of Personality and Social Psychology, 95(1), 181-196. doi:10.1037/0022-3514.95.1.181

Don, B. P., \& Mickelson, K. D. (2014). Relationship Satisfaction Trajectories Across the Transition to Parenthood Among Low-Risk Parents. Journal of Marriage and Family, 76(3), 677-692. doi:10.1111/jomf.12111

Doss, B. D., \& Rhoades, G. K. (2017). The transition to parenthood: Impact on couples' romantic relationships. Current Opinion in Psychology, 13, 25-28. doi:10.1016/j.copsyc.2016.04.003

Doss, B. D., Rhoades, G. K., Stanley, S. M., \& Markman, H. J. (2009). The effect of the transition to parenthood on relationship quality: An 8-year prospective study. Journal of Personality and Social Psychology, 96(3), 601-619. doi:10.1037/a0013969 
Duncan, T. E., Duncan, S. C., \& Strycker, L. A. (2013). An introduction to latent variable growth curve modeling: Concepts, issues, and application. Routledge Academic.

Dush, C. M. K., \& Amato, P. R. (2005). Consequences of relationship status and quality for subjective well-being. Journal of Social and Personal Relationships, 22(5), 607-627. doi:10.1177/0265407505056438

Erol, R. Y., \& Orth, U. (2011). Self-esteem development from age 14 to 30 years: A longitudinal study. Journal of Personality and Social Psychology, 101(3), 607-619. doi:10.1037/a0024299

Feeney, J. A., Hohaus, L., Noller, P., \& Alexander, R. P. (2001). Becoming parents: Exploring the bonds between mothers, fathers, and their infants. doi:10.1017/CBO9781139164511

Figueiredo, B., \& Conde, A. (2015). First- and second-time parents' couple relationship: from pregnancy to second year postpartum. Family Science, 6(1), 346-355. doi:10.1080/19424620.2015.1075894

Fox, P., \& Yamaguchi, C. (2008). Body Image Change in Pregnancy: A Comparison of Normal Weight and Overweight Primigravidas. Birth, 24(1), 35-40. doi:10.1111/j.1523536x.1997.00035.pp.x

Greenberg, J., Solomon, S., \& Pyszczynski, T. (1997). Terror Management Theory of SelfEsteem and Cultural Worldviews: Empirical Assessments and Conceptual Refinements. Advances in Experimental Social Psychology 29, 61-139. doi:10.1016/s00652601(08)60016-7 
Grote, N. K., \& Clark, M. S. (2001). Perceiving unfairness in the family: Cause or consequence of marital distress? Journal of Personality and Social Psychology, 80(2), 281-293. doi:10.1037/0022-3514.80.2.281

Grych, J. H., \& Fincham, F. D. (1990). Marital conflict and children's adjustment: A cognitivecontextual framework. Psychological bulletin, 108(2), 267. doi:10.1037/00332909.108.2.267

Hendrick, S. S. (1988). A Generic Measure of Relationship Satisfaction. Journal of Marriage and the Family, 50(1), 93. doi:10.2307/352430

Hertzog, C., \& Nesselroade, J. R. (2003). Assessing Psychological Change in Adulthood: An Overview of Methodological Issues. Psychology and Aging, 18(4), 639-657. doi:10.1037/0882-7974.18.4.639

Holman, T.B., Birch, P.J., Carroll, J.S., Doxey, C., Larson, J.H., Linford, S.T., \& Meredith, D.B. (2001). Premarital Prediction of Marital Quality or Breakup: Research, Theory, and Practice. Plenum Publishers. New York.

Hu, L. T., \& Bentler, P. M. (1998). Fit indices in covariance structure modeling: Sensitivity to underparameterized model misspecification. Psychological Methods, 3(4), 424. doi:10.1037//1082-989x.3.4.424

Jesse, D. E., Seaver, W., \& Wallace, D. C. (2003). Maternal psychosocial risks predict preterm birth in a group of women from Appalachia. Midwifery, 19(3), 191-202. doi:10.1016/s0266-6138(03)00031-7

Jomeen, J. (2004). The importance of assessing psychological status during pregnancy, childbirth and the postnatal period as a multidimensional construct: A literature review. Clinical Effectiveness in Nursing, 8(3), 143-155. doi:10.1016/j.cein.2005.02.001 
Jones, T. L., \& Prinz, R. J. (2005). Potential roles of parental self-efficacy in parent and child adjustment: A review. Clinical psychology review, 25(3), 341-363. doi:10.1016/j.cpr.2004.12.004

Katz-Wise, S. L., Priess, H. A., \& Hyde, J. S. (2010). Gender-role attitudes and behavior across the transition to parenthood. Developmental Psychology, 46(1), 18-28. doi:10.1037/a0017820

Keizer, R., \& Schenk, N. (2012). Becoming a Parent and Relationship Satisfaction: A Longitudinal Dyadic Perspective. Journal of Marriage and Family, 74(4), 759-773. doi:10.1111/j.1741-3737.2012.00991.x

Keizer, R., Dykstra, P. A., \& Poortman, A.R. (2010). The transition to parenthood and wellbeing: The impact of partner status and work hour transitions. Journal of Family Psychology, 24(4), 429-438. doi:10.1037/a0020414

Kim, S. Y., \& Kim, J. S. (2012). Investigating stage-sequential growth mixture models with multiphase longitudinal data. Structural Equation Modeling: A Multidisciplinary Journal, 19(2), 293-319. doi:10.1080/10705511.2012.659632

Kitzmann, K. M. (2000). Effects of marital conflict on subsequent triadic family interactions and parenting. Developmental psychology, 36(1), 3. doi:10.1037/0012-1649.36.1.3

Klimstra, T. A., Bleidorn, W., Asendorpf, J. B., Van Aken, M. A., \& Denissen, J. J. (2013). Correlated change of Big Five personality traits across the lifespan: A search for determinants. Journal of Research in Personality, 47(6), 768-777. doi:10.1016/j.jrp.2013.08.004 
Kotsadam, A., \& Finseraas, H. (2011). The state intervenes in the battle of the sexes: Causal effects of paternity leave. Social Science Research, 40(6), 1611-1622. doi:10.1016/j.ssresearch.2011.06.011

Krieg, D. B. (2007). Does Motherhood Get Easier the Second-Time Around? Examining Parenting Stress and Marital Quality Among Mothers Having Their First or Second Child. Parenting, 7(2), 149-175. doi:10.1080/15295190701306912

Lang, F. R., Reschke, F. S., \& Neyer, F. J. (2006). Social Relationships, Transitions, and Personality Development Across the Life Span. In D. K. Mroczek \& T. D. Little (Eds.) Handbook of Personality Development (pp. 445-466). Mahwah, NJ: Lawrence Erlbaum. doi:10.4324/9781315805610.ch22

Lawrence, E., Rothman, A. D., Cobb, R. J., Rothman, M. T., \& Bradbury, T. N. (2008). Marital satisfaction across the transition to parenthood. Journal of Family Psychology, 22(1), 4150. doi:10.1037/0893-3200.22.1.41

Leary, M. R., \& Baumeister, R. F. (2000). The nature and function of self-esteem: Sociometer theory. Advances in Experimental Social Psychology, 32, 1-62. doi:10.1016/s00652601(00)80003-9

Leary, M. R., Tambor, E. S., Terdal, S. K., \& Downs, D. L. (1995). Self-esteem as an interpersonal monitor: The sociometer hypothesis. Journal of Personality and Social Psychology, 68(3), 518-530. doi:10.1037/0022-3514.68.3.518

Lehnart, J., Neyer, F. J., \& Eccles, J. (2010). Long-Term Effects of Social Investment: The Case of Partnering in Young Adulthood. Journal of Personality, 78(2), 639-670. doi:10.1111/j.1467-6494.2010.00629.x 
LeMasters, E. E. (1957). Parenthood as Crisis. Marriage and Family Living, 19(4), 352. doi: $10.2307 / 347802$

Leventhal-Belfer, L., Cowan, P. A., \& Cowan, C. P. (1992). Satisfaction with child care arrangements: Effects on adaptation to parenthood. American Journal of Orthopsychiatry, 62(2), 165-177. doi:10.1037/h0079331

Levine, A., Zagoory-Sharon, O., Feldman, R., \& Weller, A. (2007). Oxytocin during pregnancy and early postpartum: Individual patterns and maternal-fetal attachment. Peptides, 28(6), 1162-1169. doi:10.1016/j.peptides.2007.04.016Mercer, R. T. (2004).

Luhmann, M., \& Eid, M. (2009). Does it really feel the same? Changes in life satisfaction following repeated life events. Journal of Personality and Social Psychology, 97(2), 363381. doi:10.1037/a0015809

Luhmann, M., Orth, U., Specht, J., Kandler, C., \& Lucas, R. E. (2014). Studying changes in life circumstances and personality: It's about time. European Journal of Personality, 28(3), 256-266. doi: 10.1002/per.1951.

Magnus, P., Birke, C., Vejrup, K., Haugan, A., Alsaker, E., Daltveit, A. K., ... Stoltenberg, C. (2016). Cohort Profile Update: The Norwegian Mother and Child Cohort Study (MoBa). International Journal of Epidemiology, 45(2), 382-388. doi:10.1093/ije/dyw029

Magnusson, D. (1990). Personality development from an interactional perspective. In L. Pervin (Ed.), Handbook of personality: Theory and research (pp. 193-222). New York, NY: Guilford Press.

Mercer, R. T. (2004). Becoming a mother versus maternal role attainment. Journal of nursing scholarship, 36(3), 226-232. doi:10.1111/j.1547-5069.2004.04042.x 
Meredith, W. (1993). Measurement invariance, factor analysis and factorial invariance. Psychometrika, 58(4), 525-543. doi:10.1007/bf02294825

Mitnick, D. M., Heyman, R. E., \& Smith Slep, A. M. (2009). Changes in relationship satisfaction across the transition to parenthood: A meta-analysis. Journal of Family Psychology, 23(6), 848-852. doi:10.1037/a0017004

Moller, K., Hwang, P. C., \& Wickberg, B. (2008). Couple relationship and transition to parenthood: Does workload at home matter? Journal of Reproductive and Infant Psychology, 26(1), 57-68. doi:10.1080/02646830701355782

Mund, M., Finn, C., Hagemeyer, B., Zimmermann, J., \& Neyer, F. J. (2015). The Dynamics of Self-Esteem in Partner Relationships. European Journal of Personality, 29(2), 235-249. doi:10.1002/per.1984

Muthén, L.K. and Muthén, B.O. (1998-2012). Mplus User’s Guide. Seventh Edition. Los Angeles, CA: Muthén \& Muthén

Neyer, F. J., \& Asendorpf, J. B. (2001). Personality-relationship transaction in young adulthood. Journal of Personality and Social Psychology, 81(6), 1190-1204. doi:10.1037/00223514.81.6.1190

Neyer, F. J., \& Lehnart, J. (2007). Relationships Matter in Personality Development: Evidence From an 8-Year Longitudinal Study Across Young Adulthood. Journal of Personality, 75(3), 535-568. doi:10.1111/j.1467-6494.2007.00448.

Nilsen, R. M., Vollset, S. E., Gjessing, H. K., Skjærven, R., Melve, K. K., Schreuder, P., ... \& Magnus, P. (2009). Self-selection and bias in a large prospective pregnancy cohort in Norway. Paediatric and perinatal epidemiology,23(6), 597-608. doi:10.1111/j.13653016.2009.01062.x 
Norton, R. (1983). Measuring Marital Quality: A Critical Look at the Dependent Variable. Journal of Marriage and the Family, 45(1), 141. doi:10.2307/351302

O’Brien, M., \& Peyton, V. (2002). Parenting attitudes and marital intimacy: A longitudinal analysis. Journal of Family Psychology, 16(2), 118-127. doi:10.1037/08933200.16.2.118

Öhman, S. G., Grunewald, C., \& Waldenström, U. (2003). Women's worries during pregnancy: testing the Cambridge Worry Scale on 200 Swedish women. Scandinavian Journal of Caring Sciences, 17(2), 148-152. doi: 10.1046/j.1471-6712.2003.00095.x

O'Reilly, M. M. (2004). Achieving a new balance: Women's transition to second-time parenthood. Journal of Obstetric, Gynecologic, \& Neonatal Nursing, 33(4), 455-462. doi: $10.1177 / 0884217504266911$

Orth, U., \& Robins, R. W. (2014). The Development of Self-Esteem. Current Directions in Psychological Science, 23(5), 381-387. doi:10.1177/0963721414547414

Orth, U., Robins, R. W., \& Widaman, K. F. (2012). Life-span development of self-esteem and its effects on important life outcomes. Journal of Personality and Social Psychology, 102(6), 1271-1288. doi:10.1037/a0025558

Roberts, B. W., \& Jackson, J. J. (2008). Sociogenomic Personality Psychology. Journal of Personality, 76(6), 1523-1544. doi:10.1111/j.1467-6494.2008.00530.x

Roberts, B. W., \& Wood, D. (2006). Personality Development in the Context of the NeoSocioanalytic Model of Personality. In D. K. Mroczek \& T. D. Little (Eds.), Handbook of personality development (pp. 11-39). Mahwah, NJ: Erlbaum. doi:10.4324/9781315805610.ch2 
Roberts, B. W., Wood, D., \& Smith, J. L. (2005). Evaluating Five Factor Theory and social investment perspectives on personality trait development. Journal of Research in Personality, 39(1), 166-184. doi:10.1016/j.jrp.2004.08.002

Robins, R. W., \& Trzesniewski, K. H. (2005). Self-Esteem Development Across the Lifespan. Current Directions in Psychological Science, 14(3), 158-162. doi:10.1111/j.09637214.2005.00353.x

Rodgers, R. H., \& White, J. M. (1993). Family development theory. Sourcebook of family theories and methods, 225-257. doi:10.1007/978-0-387-85764-0_10

Rosenberg, M. (1965). Society and the adolescent self-image. Princeton, NJ: Princeton University Press.

Ross, L. E., Sellers, E. M., Gilbert Evans, S. E., \& Romach, M. K. (2004). Mood changes during pregnancy and the postpartum period: development of a biopsychosocial model. Acta Psychiatrica Scandinavica, 109(6), 457-466. doi:10.1111/j.1600-0047.2004.00296.x

Røysamb, E., Vitters $\varnothing$, J., \& Tambs, K. (2014). The Relationship Satisfaction scale-psychometric properties. Norsk epidemiologi, 24(1-2), 187-194. doi:10.5324/nje.v24i1-2.1821

Rubin, R. (1984). Maternal Identity and the Maternal Experience. The American Journal of Nursing, 84(12), 1480. doi:10.1097/00000446-198412000-00030

Sanchez, L., \& Thomson, E. (1997). Becoming mothers and fathers: Parenthood, Gender, and the Division of Labor. Gender \& Society, 11(6), 747-772. doi: $10.1177 / 089124397011006003$

Schaffhuser, K., Wagner, J., Lüdtke, O., \& Allemand, M. (2014). Dyadic longitudinal interplay between personality and relationship satisfaction: A focus on neuroticism and selfesteem. Journal of Research in Personality, 53, 124-133. doi:10.1016/j.jrp.2014.08.007 
Sciangula, A., \& Morry, M. M. (2009). Self-Esteem and Perceived Regard: How I See Myself Affects My Relationship Satisfaction. The Journal of Social Psychology, 149(2), 143158. doi:10.3200/socp.149.2.143-158

Snyder, D. K. (1997). Manual for the Marital Satisfaction Inventory-Revised. Los Angeles: Western Psychological Services.

Srivastava, S., \& Beer, J. S. (2005). How self-evaluations relate to being liked by others: Integrating sociometer and attachment perspectives. Journal of Personality and Social Psychology, 89(6), 966-977. doi:10.1037/0022-3514.89.6.966

Statham, H., Green, J. M., \& Kafetsios, K. (1997). Who Worries That Something Might Be Wrong With the Baby? A Prospective Study of 1072 Pregnant Women. Birth, 24(4), 223-233. doi:10.1111/j.1523-536x.1997.tb00595.x

Tambs, K., \& Røysamb, E. (2014). Selection of questions to short-form versions of original psychometric instruments in MoBa. Norsk epidemiologi, 24(1-2). doi:10.5324/nje.v24i12.1822

Tambs, K. (2004). Valg av spørsmål til kortversjoner av etablerte psykometriske instrumenter. Ed. I. Sandanger, G. Ingebrigtsen, J.F. Nygård and K. Sørgyrd. Ubevisst sjeleliv og bevisst samfunnsliv. Psykisk hele i en sammenheng. Festskrift til Tom Sørensen på hans 60-års dag, 217-229. Nittedal: Nordkyst Psykiatrisk AS.

Tiggemann, M. (2004). Body image across the adult life span: stability and change. Body Image, 1(1), 29-41. doi:10.1016/s1740-1445(03)00002-0

Twenge, J. M., Campbell, W. K., \& Foster, C. A. (2003). Parenthood and Marital Satisfaction: A Meta-Analytic Review. Journal of Marriage and Family, 65(3), 574-583. doi:10.1111/j.1741-3737.2003.00574.x 
Umberson, D., Williams, K., Powers, D. A., Chen, M. D., \& Campbell, A. M. (2005). As Good as it Gets? A Life Course Perspective on Marital Quality. Social Forces, 84(1), 493-511. doi:10.1353/sof.2005.0131

VanLaningham, J., Johnson, D. R., \& Amato, P. (2001). Marital Happiness, Marital Duration, and the U-Shaped Curve: Evidence from a Five-Wave Panel Study. Social Forces, 79(4), 1313-1341. doi:10.1353/sof.2001.0055

van Scheppingen, M. A., Jackson, J. J., Specht, J., Hutteman, R., Denissen, J. J. A., \& Bleidorn, W. (2016). Personality development during the transition to parenthood: A test of social investment theory. Social Psychological and Personality Science, 7, 452-462. doi:10.1177/1948550616630032

Wagner, J., Becker, M., Lüdtke, O., \& Trautwein, U. (2015). The First Partnership Experience and Personality Development. Social Psychological and Personality Science, 6(4), 455463. doi: $10.1177 / 1948550614566092$

Wagner, J., Lüdtke, O., Jonkmann, K., \& Trautwein, U. (2013). Cherish yourself: Longitudinal patterns and conditions of self-esteem change in the transition to young adulthood. Journal of Personality and Social Psychology, 104(1), 148-163. doi:10.1037/a0029680

Widaman, K. F., Ferrer, E., \& Conger, R. D. (2010). Factorial invariance within longitudinal structural equation models: Measuring the same construct across time. Child Development Perspectives, 4(1), 10-18. doi:10.1111/j.1750-8606.2009.00110.x

Wilkinson, R. B. (1995). Changes in psychological health and the marital relationship through childbearing: Transition or process as stressor? Australian Journal of Psychology, 47(2), 86-92. doi:10.1080/00049539508257505 
Wright, P.J., Henggeler, S. W., \& Craig, L. (1986). Problems in paradise?: A longitudinal examination of the transition to parenthood. Journal of Applied Developmental Psychology, 7(3), 277-291. doi:10.1016/0193-3973(86)90035-3

Wrzus, C., Hänel, M., Wagner, J., \& Neyer, F. J. (2013). Social network changes and life events across the life span: A meta-analysis. Psychological Bulletin, 139(1), 53-80. doi:10.1037/a0028601

Wrzus, C., \& Roberts, B. W. (2016). Processes of Personality Development in Adulthood: The TESSERA Framework. Personality and Social Psychology Review. doi:10.1177/1088868316652279 
Table 1

T-scores for Self-Esteem and Relationship Satisfaction Across all Time-points for Four Subgroups of Mothers

\begin{tabular}{|c|c|c|c|c|c|c|c|}
\hline Variable & & $\begin{array}{c}\mathrm{T} 1 \\
M(S D)\end{array}$ & $\begin{array}{c}\mathrm{T} 2 \\
M(S D)\end{array}$ & $\begin{array}{c}\mathrm{T} 3 \\
M(S D)\end{array}$ & $\begin{array}{c}\mathrm{T} 4 \\
M(S D)\end{array}$ & $\begin{array}{c}\mathrm{T} 5 \\
M(S D)\end{array}$ & $\begin{array}{c}\text { Difference } \\
\text { T1-T5 }\end{array}$ \\
\hline \multirow[t]{4}{*}{ Self-Esteem } & $\begin{array}{c}\text { First } \\
\text { Pregnancy }\end{array}$ & $\begin{array}{l}50.74 \\
(9.93)\end{array}$ & $\begin{array}{l}49.21 \\
(9.66)\end{array}$ & $\begin{array}{c}50.94 \\
(10.17)\end{array}$ & $\begin{array}{c}50.15 \\
(10.26)\end{array}$ & $\begin{array}{c}49.33 \\
(10.42)\end{array}$ & -1.42 \\
\hline & $\begin{array}{c}\text { Second } \\
\text { Pregnancy }\end{array}$ & $\begin{array}{l}50.15 \\
(9.79)\end{array}$ & $\begin{array}{l}48.41 \\
(9.50)\end{array}$ & $\begin{array}{c}50.28 \\
(10.11)\end{array}$ & $\begin{array}{c}49.67 \\
(10.07)\end{array}$ & $\begin{array}{c}48.92 \\
(10.41)\end{array}$ & -1.23 \\
\hline & $\begin{array}{c}\text { Third } \\
\text { Pregnancy }\end{array}$ & $\begin{array}{l}50.23 \\
(9.93)\end{array}$ & $\begin{array}{l}48.53 \\
(9.59)\end{array}$ & $\begin{array}{c}50.28 \\
(10.06)\end{array}$ & $\begin{array}{l}49.97 \\
(9.99)\end{array}$ & $\begin{array}{c}48.85 \\
(10.46)\end{array}$ & -1.37 \\
\hline & $\begin{array}{c}\text { Fourth } \\
\text { Pregnancy }\end{array}$ & $\begin{array}{c}49.39 \\
(10.27)\end{array}$ & $\begin{array}{l}47.67 \\
(9.96)\end{array}$ & $\begin{array}{c}49.64 \\
(10.36)\end{array}$ & $\begin{array}{c}48.98 \\
(10.91)\end{array}$ & $\begin{array}{c}48.03 \\
(11.02)\end{array}$ & -1.35 \\
\hline \multirow[t]{4}{*}{$\begin{array}{l}\text { Relationship } \\
\text { Satisfaction }\end{array}$} & $\begin{array}{c}\text { First } \\
\text { Pregnancy }\end{array}$ & $\begin{array}{l}52.53 \\
(8.36)\end{array}$ & $\begin{array}{l}53.05 \\
(7.96)\end{array}$ & $\begin{array}{l}50.82 \\
(9.97)\end{array}$ & $\begin{array}{c}49.22 \\
(10.94)\end{array}$ & $\begin{array}{c}47.74 \\
(11.73)\end{array}$ & -4.79 \\
\hline & $\begin{array}{c}\text { Second } \\
\text { Pregnancy }\end{array}$ & $\begin{array}{l}49.11 \\
(9.75)\end{array}$ & $\begin{array}{l}49.56 \\
(9.54)\end{array}$ & $\begin{array}{c}48.68 \\
(10.65)\end{array}$ & $\begin{array}{c}47.69 \\
(11.39)\end{array}$ & $\begin{array}{c}46.49 \\
(12.11)\end{array}$ & -2.62 \\
\hline & $\begin{array}{c}\text { Third } \\
\text { Pregnancy }\end{array}$ & $\begin{array}{l}49.14 \\
(9.80)\end{array}$ & $\begin{array}{l}49.68 \\
(9.84)\end{array}$ & $\begin{array}{c}48.98 \\
(10.75)\end{array}$ & $\begin{array}{c}48.33 \\
(11.36)\end{array}$ & $\begin{array}{c}46.73 \\
(11.99)\end{array}$ & -2.41 \\
\hline & $\begin{array}{c}\text { Fourth } \\
\text { Pregnancy }\end{array}$ & $\begin{array}{c}49.18 \\
(10.49)\end{array}$ & $\begin{array}{c}49.69 \\
(10.70)\end{array}$ & $\begin{array}{c}48.75 \\
(11.29)\end{array}$ & $\begin{array}{c}48.14 \\
(11.83)\end{array}$ & $\begin{array}{c}46.27 \\
(13.07)\end{array}$ & -2.91 \\
\hline
\end{tabular}

Note. T1 and T2 represent the first and second time-point, during the $18^{\text {th }}$ and $30^{\text {th }}$ week of pregnancy. T3, T4 and T5 represent the three time-points after birth, when the child was 6 months, 18 months and 36 months of age, respectively. 
Table 2

Descriptive Statistics of Moderator Variables for Four Subgroups of Mothers

\begin{tabular}{|c|c|c|c|c|}
\hline & $\begin{array}{c}\text { First } \\
\text { Pregnancy }\end{array}$ & $\begin{array}{c}\text { Second } \\
\text { Pregnancy }\end{array}$ & $\begin{array}{c}\text { Third } \\
\text { Pregnancy }\end{array}$ & $\begin{array}{c}\text { Fourth } \\
\text { Pregnancy }\end{array}$ \\
\hline Variable & $M(S D) / N(\%)$ & $M(S D) / N(\%)$ & $M(S D) / N(\%)$ & $M(S D) / N(\%)$ \\
\hline \multicolumn{5}{|l|}{ Individual-Level } \\
\hline Age Mother & $28.04(4.53)$ & $30.47(4.08)$ & $34.72(3.88)$ & $32.72(3.74)$ \\
\hline Education Level Mother (z-score) & $0.07(0.97)$ & $0.00(0.98)$ & $-0.53(1.17)$ & $-0.15(1.06)$ \\
\hline Paid Employment ( 1 = yes $)$ & $38,095(91.72)$ & $20,336(89.61)$ & $8,712(87.65)$ & $1,632(65.59)$ \\
\hline Civil Status ( 1 = married/co-habiting) & $43,030(95.05)$ & $24,807(97.72)$ & $10,909(97.76)$ & $2,384(96.40)$ \\
\hline \multicolumn{5}{|l|}{ Pregnancy Related } \\
\hline Planned Pregnancy (1 = planned) & $35,841(79.37)$ & $21,860(86.16)$ & $8,511(76.48)$ & $1,477(60.16)$ \\
\hline Pre-term birth $(1=$ pre-term $)$ & $2,416(6.75)$ & $880(4.88)$ & $383(4.93)$ & $92(5.71)$ \\
\hline \multicolumn{5}{|l|}{ Post-Birth Variables } \\
\hline Gender Child $(1=$ girl $)$ & $18,901(49.09)$ & $9,190(49.42)$ & $3,886(48.56)$ & $829(49.58)$ \\
\hline Difficult temperament (z-sore) & $0.08(0.99)$ & $-0.06(1.01)$ & $-0.15(1.00)$ & $-0.16(0.99)$ \\
\hline
\end{tabular}

Note. Data is presented as $M(S D)$ for continuous variables. For dichotomous variables, the number and percentage of people with a value of 1 are reported. $\mathrm{T} 1=$ the first time-point at the $18^{\text {th }}$ week of pregnancy. 
Table 3

BIC Values of Eight Change Models for Self-Esteem and Relationship Satisfaction

\begin{tabular}{|c|c|c|c|}
\hline \multirow[b]{2}{*}{ Model } & & Self-Esteem & $\begin{array}{l}\text { Relationship } \\
\text { Satisfaction }\end{array}$ \\
\hline & & $\mathrm{BIC}$ & $\mathrm{BIC}$ \\
\hline \multirow[b]{2}{*}{ No change after birth } & $1 \mathrm{a}$ & 2333730.614 & 2273930.072 \\
\hline & $2 \mathrm{a}$ & 2333582.631 & 2261964.867 \\
\hline \multirow[b]{2}{*}{ Sudden change } & $1 b$ & 2333346.928 & 2264215.859 \\
\hline & $2 b$ & 2331432.883 & 2261593.673 \\
\hline \multirow[b]{2}{*}{ Gradual change } & $1 \mathrm{c}$ & 2333646.745 & 2261431.053 \\
\hline & $2 \mathrm{c}$ & 2332616.663 & 2261265.146 \\
\hline \multirow{3}{*}{ Sudden and gradual } & $1 d$ & 2331970.559 & 2261077.526 \\
\hline & $2 d$ & 2329124.157 & 2260678.343 \\
\hline & $2 \mathrm{~d}$ (final) & 2326880.467 & 2248748.823 \\
\hline
\end{tabular}

Note. In Model 1a-2d, the variances and covariances of all slopes were fixed. In Model 2d (final), the variances of the second and third slope were freely estimated (see Footnote 2). 
Table 4

Parameter Estimates of the Best-Fitting Model (2d) for Self-Esteem and Relationship Satisfaction

\begin{tabular}{|c|c|c|c|c|c|c|c|c|}
\hline \multirow[b]{2}{*}{ Parameter } & \multicolumn{4}{|c|}{ Self-Esteem } & \multicolumn{4}{|c|}{ Relationship Satisfaction } \\
\hline & $B$ & S.E. & $95 \% \mathrm{CI}$ & Var & $B$ & S.E. & $95 \% \mathrm{CI}$ & Var \\
\hline Intercept & 50.46 & 0.03 & $\begin{array}{c}{[50.65} \\
50.84]\end{array}$ & 62.58 & 50.96 & 0.03 & $\begin{array}{c}{[50.89} \\
51.02]\end{array}$ & 63.10 \\
\hline Linear $\Delta 1$ & -6.49 & 0.12 & $\begin{array}{l}{[-6.45} \\
-5.83]\end{array}$ & - & 1.98 & 0.09 & $\begin{array}{l}{[1.80,} \\
2.16]\end{array}$ & - \\
\hline Linear $\Delta 2$ & 2.48 & 0.04 & $\begin{array}{l}{[2.26,} \\
2.49]\end{array}$ & 19.27 & -2.28 & 0.04 & $\begin{array}{l}{[-2.36,} \\
-2.20]\end{array}$ & 45.75 \\
\hline Linear $\Delta 3$ & -0.60 & 0.02 & $\begin{array}{l}{[-0.68} \\
-0.60]\end{array}$ & 2.99 & -1.08 & 0.02 & $\begin{array}{l}{[-1.11} \\
-1.04]\end{array}$ & 8.01 \\
\hline
\end{tabular}

Note. All $B$ 's and variances were significant at $p<.001$. Intercept $=$ level at T1; Linear $\Delta 1=$ linear change during pregnancy; Linear $\Delta 2=$ linear change around childbirth; Linear $\Delta 3=$ linear change after childbirth. Linear change was parametrized in T-scores per year, with of 2, 5, and $8 \mathrm{~T}$-scores representing small, medium, and large effects, respectively. The variance of the first slope was fixed (see Footnote 2). 
Table 5

Initial Correlation and Correlated Change between Self-Esteem and Relationship Satisfaction

\section{Self-Esteem}

Intercept Linear $\Delta 1$ Linear $\Delta 2$ Linear $\Delta 3$

$\begin{array}{cccccc} & \text { Intercept } & .40 * * * & - & .01 & -.07 * * * \\ & & & & & \\ \begin{array}{c}\text { Relationship } \\ \text { satisfaction }\end{array} & \text { Linear } \Delta 1 & - & - & - & - \\ & \text { Linear } \Delta 2 & .08 * * * & - & .39 * * * & -.10 * * * \\ & & & & & \\ & \text { Linear } \Delta 3 & -.01 & - & .02 & .34 * * *\end{array}$

Note. The linear slopes during pregnancy could not be correlated due to fixed variance (see Footnote 2). Intercept = level at T1; Linear $\Delta 1=$ linear change during pregnancy; Linear $\Delta 2=$ linear change around childbirth; Linear $\Delta 3=$ linear change after childbirth. $* p<.05 * * p<.01 * * * p<.001$ 
Table 6

Moderating Effects of Individual-Level Variables, Pregnancy-Related Variables, and Post-Birth Variables on Self-Esteem Trajectories

Intercept $\quad$ Linear $\Delta 2 \quad$ Linear $\Delta 3$

Parameter

\begin{tabular}{llllllllll}
\hline B & S.E. & $95 \% \mathrm{CI}$ & B & S.E. & $95 \% \mathrm{CI}$ & B & S.E. & $95 \% \mathrm{CI}$
\end{tabular}

Individual-Level

\begin{tabular}{|c|c|c|c|c|c|c|c|c|c|}
\hline Age & $-0.23 * * *$ & 0.01 & $\begin{array}{l}{[-0.25,} \\
-0.22]\end{array}$ & $0.09 * * *$ & 0.01 & $\begin{array}{l}{[0.07} \\
0.10]\end{array}$ & $-0.04 * * *$ & 0.00 & $\begin{array}{r}{[-0.04,} \\
-0.03]\end{array}$ \\
\hline Education level & $0.65 * * *$ & 0.03 & $\begin{array}{r}{[0.59} \\
0.72]\end{array}$ & 0.06 & 0.04 & $\begin{array}{r}{[-0.03} \\
0.15]\end{array}$ & $0.13 * * *$ & 0.02 & $\begin{array}{r}{[0.08,} \\
0.17]\end{array}$ \\
\hline $\begin{array}{l}\text { Paid employment } \\
(1=\text { yes })\end{array}$ & $0.80 * * *$ & 0.11 & $\begin{array}{r}{[0.58,} \\
1.02]\end{array}$ & $0.31 *$ & 0.15 & $\begin{array}{l}{[0.01,} \\
0.61]\end{array}$ & -0.13 & 0.07 & $\begin{array}{r}{[-0.28} \\
0.01]\end{array}$ \\
\hline $\begin{array}{l}\text { Civil status } \\
(1=\text { married/co- } \\
\text { habiting })\end{array}$ & $9.95 * * *$ & 0.20 & $\begin{array}{l}{[9.56,} \\
10.34]\end{array}$ & $-1.39 * * *$ & 0.30 & $\begin{array}{l}{[-1.97,} \\
-0.81]\end{array}$ & $-0.60 * * *$ & 0.14 & $\begin{array}{r}{[-0.88,} \\
-0.33]\end{array}$ \\
\hline egnancy Related & & & & & & & & & \\
\hline $\begin{array}{l}\text { Planned } \\
\text { Pregnancy } \\
(1 \text { = planned })\end{array}$ & $3.48 * * *$ & 0.09 & $\begin{array}{r}{[3.31,} \\
3.65]\end{array}$ & 0.18 & 0.11 & $\begin{array}{r}{[-0.04} \\
0.39]\end{array}$ & $-0.16 * * *$ & 0.05 & $\begin{array}{r}{[-0.26} \\
-0.06]\end{array}$ \\
\hline $\begin{array}{l}\text { Pre-term birth } \\
(1=\text { pre-term })\end{array}$ & 0.13 & 0.14 & $\begin{array}{r}{[-0.14} \\
0.41]\end{array}$ & $-0.56 * * *$ & 0.17 & $\begin{array}{l}{[-0.90} \\
-0.22]\end{array}$ & $-0.18 *$ & 0.08 & $\begin{array}{r}{[-0.34,} \\
-0.02]\end{array}$ \\
\hline
\end{tabular}

Post-birth variables

\begin{tabular}{|c|c|c|c|c|c|c|c|c|}
\hline $\begin{array}{l}\text { Gender child } \\
(1=\text { girl })\end{array}$ & -0.09 & 0.07 & $\begin{array}{r}{[-0.22,} \\
0.04]\end{array}$ & 0.11 & 0.08 & $\begin{array}{r}{[-0.04} \\
0.27]\end{array}$ & 0.02 & 0.04 \\
\hline $\begin{array}{l}\text { Difficult } \\
\text { temperament }\end{array}$ & $-0.92 * * *$ & 0.03 & $\begin{array}{r}{[-0.99,} \\
-0.86]\end{array}$ & $-0.99 * * *$ & 0.04 & $\begin{array}{l}{[-1.07} \\
-0.91]\end{array}$ & $0.07 * * *$ & 0.02 \\
\hline
\end{tabular}

Note. The variance of the linear slope during pregnancy was fixed and therefore not correlated with the moderator variables (see Footnote 2 ). Intercept $=$ level at $\mathrm{T} 1$; Linear $\Delta 2=$ linear change around childbirth; Linear $\Delta 3=$ linear change after childbirth.

$* p<.05 * * p<.01 * * * p<.001$ 
Table 7

Moderating Effects of Individual-Level Variables, Pregnancy-Related Variables, and Post-Birth Variables on Relationship Satisfaction Trajectories

$\begin{array}{lll}\text { Intercept } & \text { Linear } \Delta 2 & \text { Linear } \Delta 3\end{array}$

Parameter

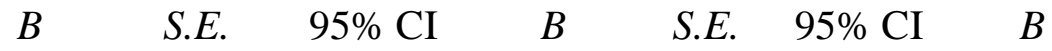

S.E. $\quad 95 \% \mathrm{CI}$

Individual-Level

\begin{tabular}{|c|c|c|c|c|c|c|c|c|c|}
\hline Age & $0.11 * * *$ & 0.01 & $\begin{array}{l}{[0.09} \\
0.12]\end{array}$ & $-0.05 * * *$ & 0.01 & $\begin{array}{l}{[-0.07,} \\
-0.03]\end{array}$ & $-0.01 *$ & 0.00 & $\begin{array}{r}{[-0.02,} \\
0.00]\end{array}$ \\
\hline Education level & $1.35 * * *$ & 0.04 & $\begin{array}{r}{[1.28,} \\
1.42]\end{array}$ & -0.07 & 0.05 & $\begin{array}{r}{[-0.16} \\
0.02]\end{array}$ & $0.06 * * *$ & 0.02 & $\begin{array}{r}{[0.03} \\
0.10]\end{array}$ \\
\hline $\begin{array}{l}\text { Paid employment } \\
(1=\text { yes })\end{array}$ & $2.17 * * *$ & 0.12 & $\begin{array}{l}{[1.94,} \\
2.40]\end{array}$ & -0.11 & 0.15 & $\begin{array}{r}{[-0.41} \\
0.18]\end{array}$ & -0.07 & 0.07 & $\begin{array}{r}{[-0.20,} \\
0.05]\end{array}$ \\
\hline $\begin{array}{l}\text { Civil status } \\
(1=\text { married/co- } \\
\text { habiting })\end{array}$ & $2.16^{* * * *}$ & 0.18 & $\begin{array}{l}{[1.81} \\
2.52]\end{array}$ & $-0.74 * * *$ & 0.23 & $\begin{array}{l}{[-1.19} \\
-0.28]\end{array}$ & -0.02 & 0.10 & $\begin{array}{r}{[-0.21,} \\
0.18]\end{array}$ \\
\hline nancy related & & & & & & & & & \\
\hline $\begin{array}{l}\text { Planned } \\
\text { Pregnancy } \\
(1=\text { planned })\end{array}$ & $2.38 * * *$ & 0.09 & $\begin{array}{l}{[2.20,} \\
2.56]\end{array}$ & 0.05 & 0.11 & $\begin{array}{r}{[-0.17,} \\
0.26]\end{array}$ & $-0.09 *$ & 0.04 & $\begin{array}{r}{[-0.18,} \\
-0.01]\end{array}$ \\
\hline $\begin{array}{l}\text { Pre-term birth } \\
(1=\text { pre-term })\end{array}$ & $-0.30^{*}$ & 0.15 & $\begin{array}{l}{[-0.59} \\
-0.01]\end{array}$ & -0.23 & 0.18 & $\begin{array}{c}{[-0.57} \\
0.11\end{array}$ & $-0.16^{*}$ & 0.07 & $\begin{array}{r}{[-0.30,} \\
-0.02]\end{array}$ \\
\hline
\end{tabular}

Post-birth variables

\begin{tabular}{|c|c|c|c|c|c|c|c|c|c|}
\hline $\begin{array}{l}\text { Gender child } \\
(1=\text { girl })\end{array}$ & -0.01 & 0.07 & $\begin{array}{r}{[-0.15,} \\
0.12]\end{array}$ & 0.09 & 0.08 & $\begin{array}{r}{[-0.06} \\
0.25]\end{array}$ & 0.00 & 0.03 & $\begin{array}{r}{[-0.07,} \\
0.06]\end{array}$ \\
\hline $\begin{array}{l}\text { Difficult } \\
\text { temperament }\end{array}$ & $-1.47 * * *$ & 0.03 & $\begin{array}{l}{[-1.54,} \\
-1.40]\end{array}$ & $-0.79 * * *$ & 0.04 & $\begin{array}{r}{[-0.87} \\
-0.71]\end{array}$ & $0.15 * * *$ & 0.02 & $\begin{array}{r}{[0.12,} \\
0.19]\end{array}$ \\
\hline
\end{tabular}

* Note. The variance of the linear slope during pregnancy was fixed and therefore not correlated with the moderator variables (see Footnote 2). Intercept $=$ level at $\mathrm{T} 1$; Linear $\Delta 2=$ linear change around childbirth; Linear $\Delta 3=$ linear change after childbirth.

$* p<.05 * * p<.01 * * * p<.001$ 
No change after birth

$1 \mathrm{a}$
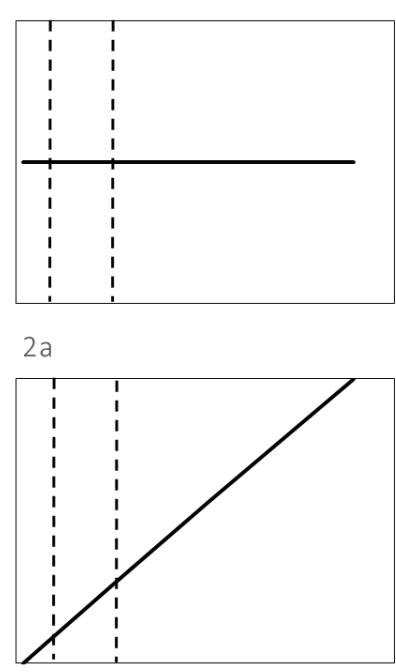

Sudden change after birth

$1 b$

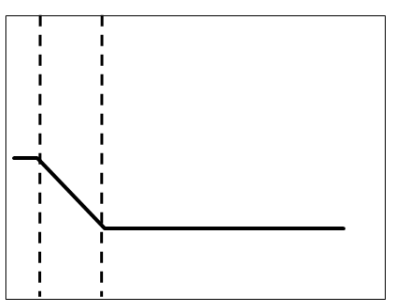

$2 b$

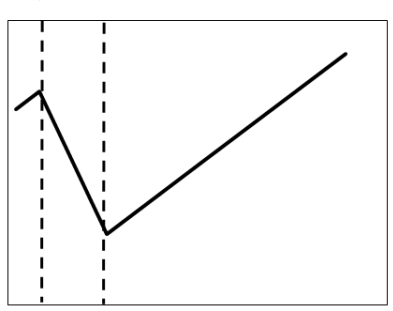

Gradual change after birth

$1 \mathrm{c}$

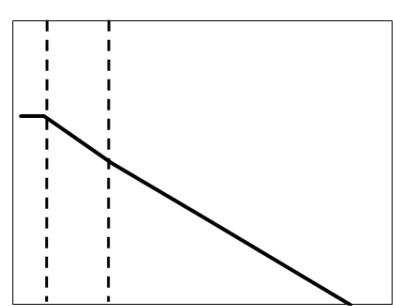

$2 c$

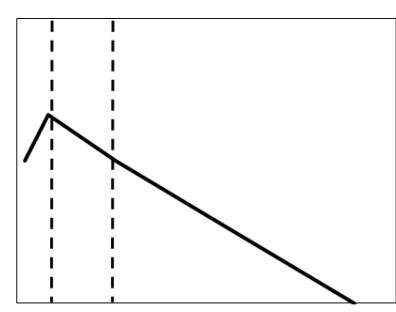

Sudden and gradual change

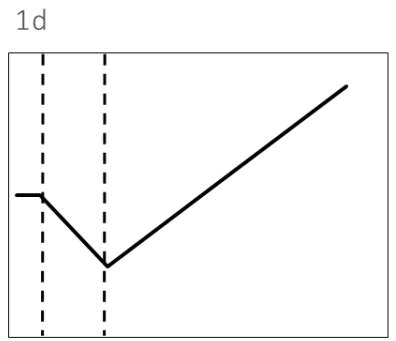

$2 d$

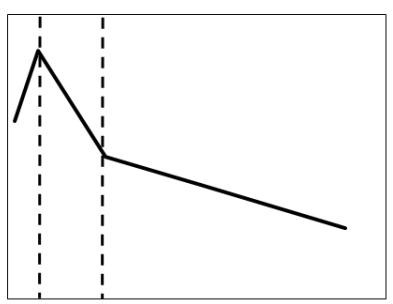

Figure 1. Conceptual models of change over the transition to motherhood. Childbirth took place during the period between the two dotted lines (i.e., between T2 at the $30^{\text {th }}$ week of pregnancy, and T3 when the child was 6 months old). The solid lines represent changes in self-esteem or relationship satisfaction. The length of each phase is based on the unequal time-intervals in the data. The linear changes could have been positive or negative in direction (adapted from Doss et al., 2009 and Bleidorn, Buyukcan-Tetik, et al., 2016). 


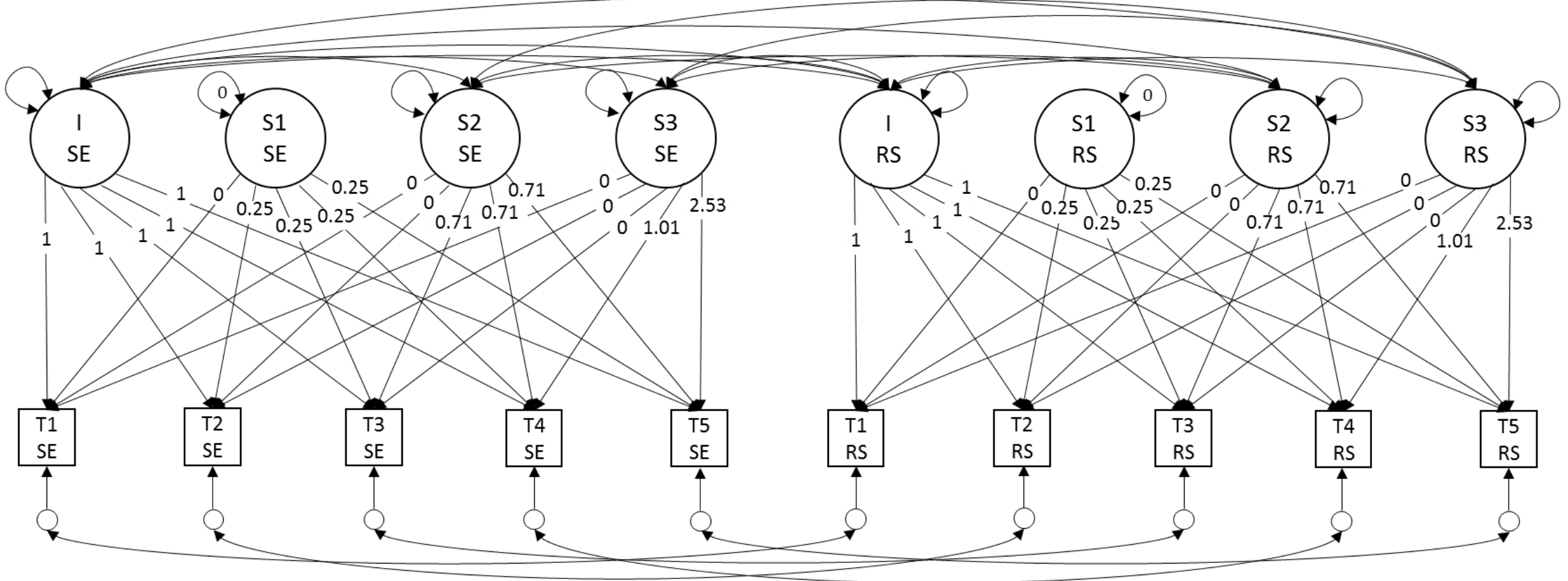

Figure 2. Parallel process piecewise latent growth curve model used to estimate the intercepts (I) and slopes (S1, S2, S3) for selfesteem (SE) and relationship satisfaction (RS) in Model 2d. The variances of the first slopes (S1) were constrained to allow model estimation. The manifest variables of self-esteem and relationship satisfaction were allowed to covary at every assessment wave.

(C) 2017, American Psychological Association. This paper is not the copy of record and may not exactly replicate the final, authoritative version of the article. Please do not copy or cite without authors permission. The final article will be available, upon publication, via its DOI: $10.1037 / \mathrm{pspp} 0000156$. 


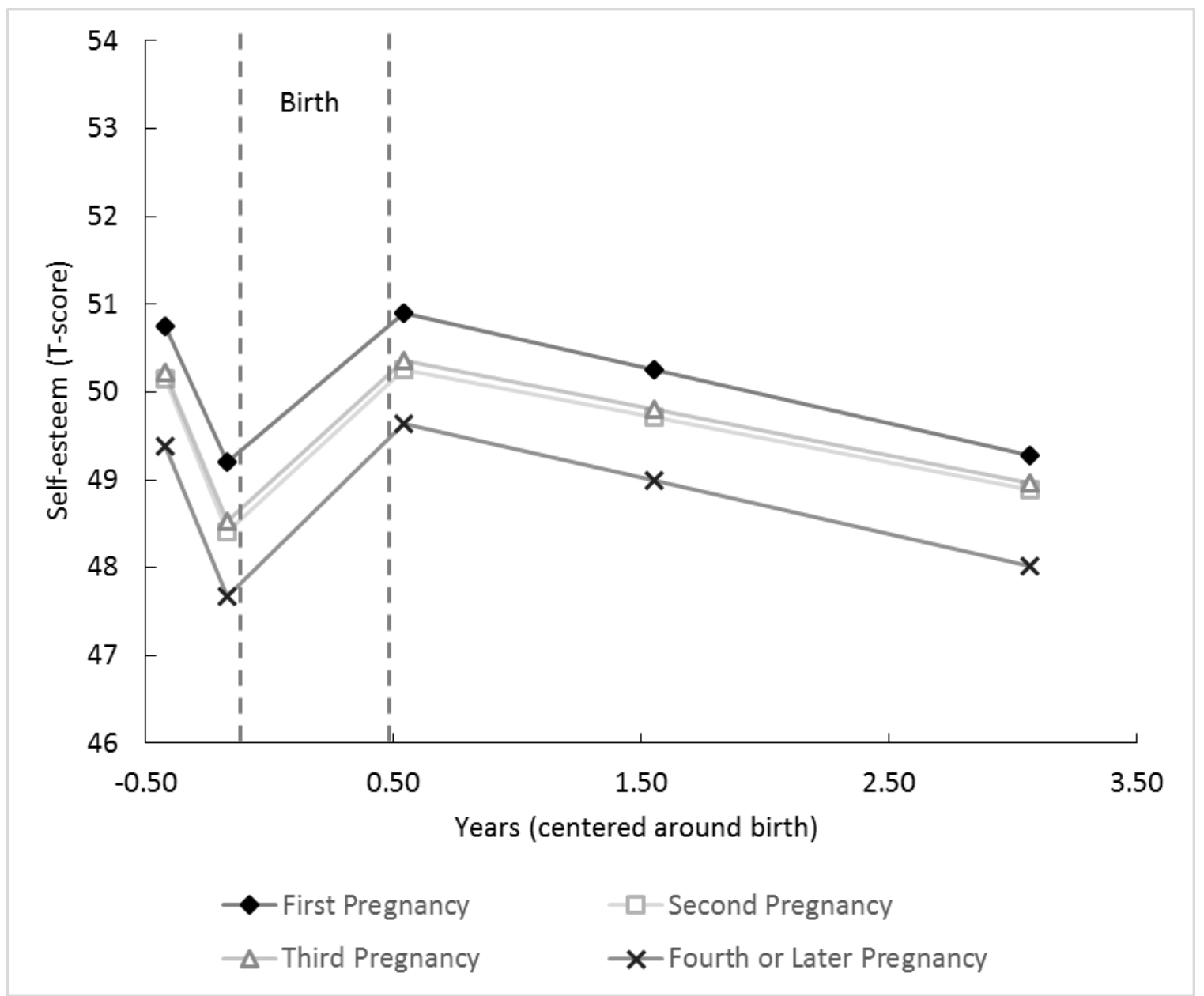

Figure 3. Estimated change in self-esteem for the four subgroups of mothers experiencing their first, second, third, fourth, or later pregnancy. Childbirth took place during the period between the two dotted lines.

(C) 2017, American Psychological Association. This paper is not the copy of record and may not exactly replicate the final, authoritative version of the article. Please do not copy or cite without authors permission. The final article will be available, upon publication, via its DOI: $10.1037 / \mathrm{pspp} 0000156$. 


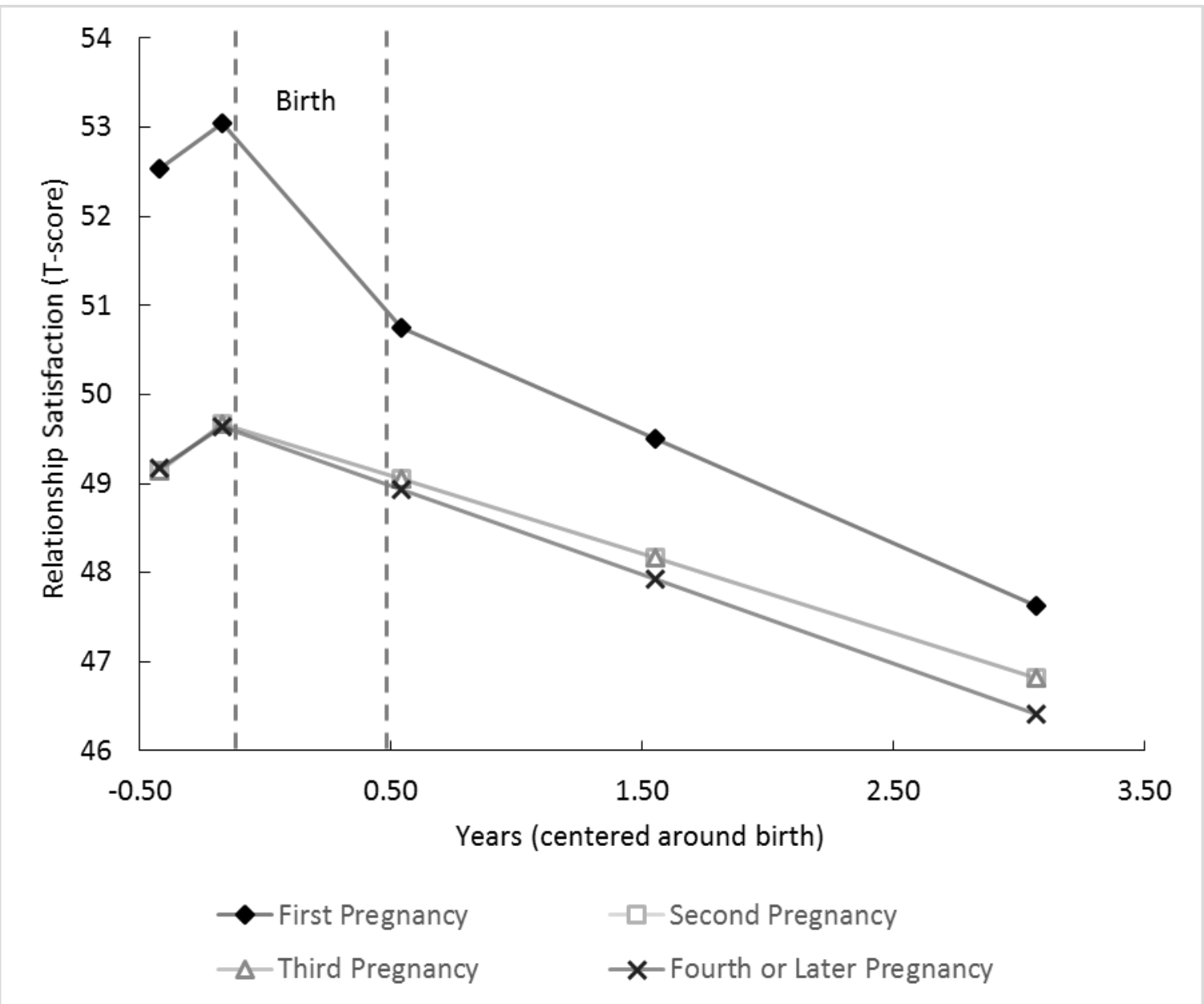

Figure 4. Estimated change in relationship satisfaction for the four subgroups of mothers experiencing their first, second, third, fourth, or later pregnancy. Childbirth took place during the period between the two dotted lines. 


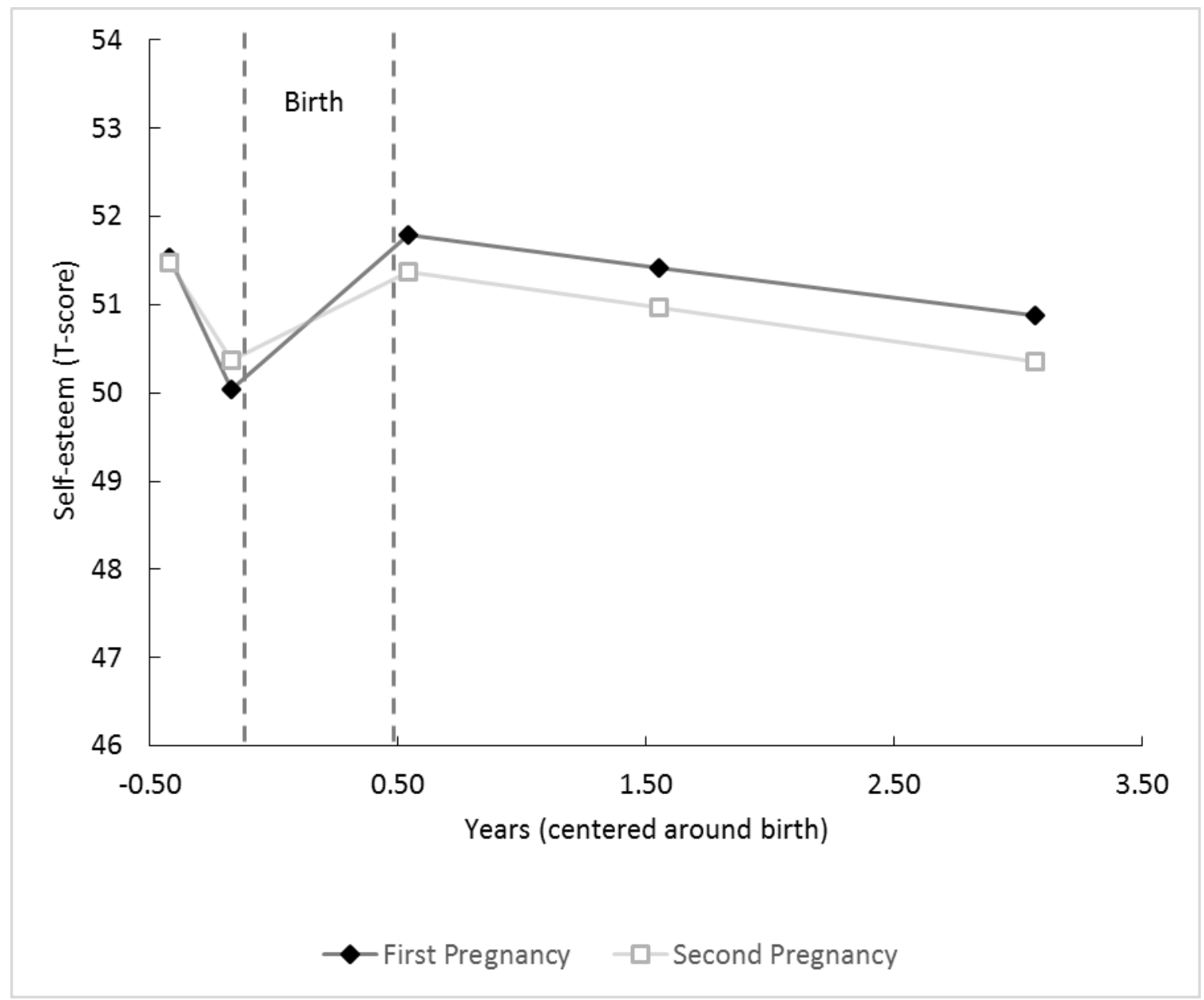

Figure 5. Estimated change in self-esteem within mothers that participated with their first and second pregnancy. Childbirth took place during the period between the two dotted lines. 


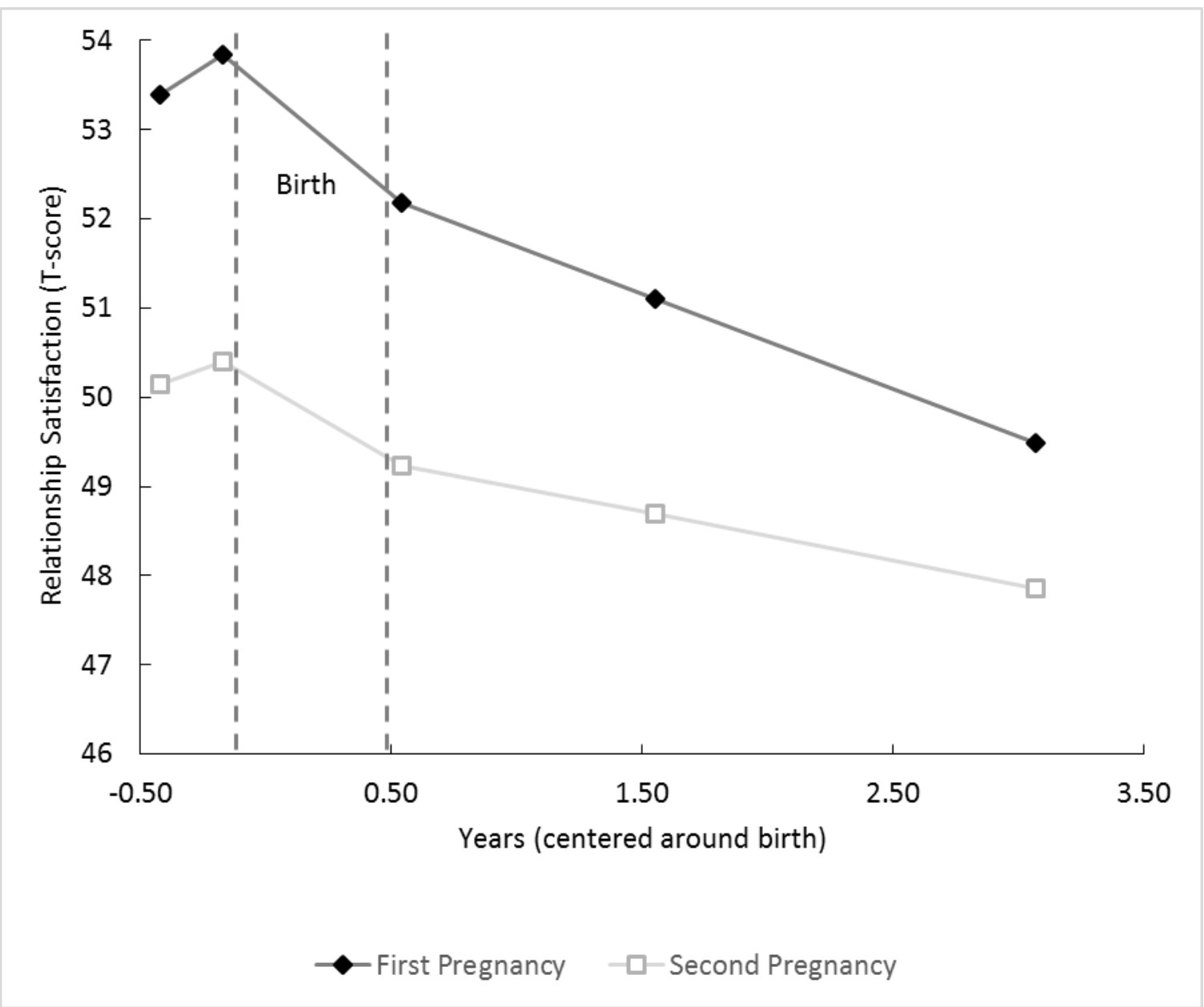

Figure 6. Estimated change in relationship satisfaction within mothers that participated with their first and second pregnancy. Childbirth took place during the period between the two dotted lines. 